This PDF is a selection from an out-of-print volume from the National Bureau of Economic Research

Volume Title: Risk Aspects of Investment-Based Social Security Reform Volume Author/Editor: John Y. Campbell and Martin Feldstein, editors Volume Publisher: University of Chicago Press

Volume ISBN: 0-226-09255-0

Volume URL: http://www.nber.org/books/camp01-1

Publication Date: January 2001

Chapter Title: The Role of International Investment in a Privatized Social Security System

Chapter Author: Marianne Baxter, Robert G. King

Chapter URL: http://www.nber.org/chapters/c10599

Chapter pages in book: (p. 371 - 438) 


\title{
The Role of International \\ Investment in a Privatized \\ Social Security System
}

\author{
Marianne Baxter and Robert G. King
}

Many proposals to reform the current social security system would permit the investment of retirement funds in risky assets such as equities. Under some proposals, the government would invest in risky assets on the individual's behalf. Under other proposals, these assets would be managed directly by the individual in a "private retirement account" (PRA). In each case, however, the idea is that including risky assets could improve the welfare of social security participants because these assets yield higher returns on average. This paper asks whether there is an important role for international financial assets in a privatized social security system. We find that there are two important reasons to incorporate international investment into reform proposals for social security: diversification benefits and risk-management or hedging benefits. We provide empirical and quantitative work aimed at assessing each of these benefits.

The first reason to invest in international financial assets is that there are well-known benefits from international diversification. A diversified world portfolio yields lower risk for a given expected return than a portfolio of any single nation, even a large nation such as the United States. These diversification benefits are potentially important both for working individuals and for retirees.

The second source of benefits from investing in foreign risky assetsrisk-management or hedging benefits - is less frequently discussed. We show that foreign assets may be useful in hedging risk associated with nontraded assets, the most important of which are human capital and

Marianne Baxter is professor of economics at Boston University and a research associate of the National Bureau of Economic Research. Robert G. King is professor of economics at Boston University and a research associate of the National Bureau of Economic Research. 
social security. With respect to human capital, the risk derives from uncertainty regarding future labor income. We show that the unexpected movements in labor income are positively correlated with unexpected changes in U.S. aggregate economic activity and are also positively correlated with returns on U.S. risky financial assets. By contrast, unexpected movements in U.S. labor income are less highly correlated with the returns on foreign financial assets. Intuitively, then, a portfolio containing foreign assets will be helpful to U.S. workers in managing the risk of the returns on total wealth, including human wealth.

The second important nontraded asset is the current social security system itself. It appears likely that a reformed social security system will retain elements of the current system, with mandatory "contributions" during one's working life and payouts during the retirement period tied to individual and aggregate labor income histories. As we make clear below, the current social security system contains an important element of aggregate risk that could potentially be managed with foreign assets in a way similar to the hedging of labor income risk described above.

The paper is structured as follows. Section 10.1 provides an overview of social security, focusing on the nature of its cash flows. We show that the current social security claim resembles a flexible-premium deferred variable annuity. Unlike private market annuity products, the rate of return on social security is related to the growth of aggregate labor income rather than being linked to the return on marketable financial assets.

Section 10.2 begins to address the diversification issue by exploring the consequences of allowing individuals to add risky assets to their retirement portfolios. Using data on U.S. and foreign asset returns, we evaluate the extent to which individuals could improve their risk-return trade-off by investing in foreign securities.

Section 10.3 provides evidence on the behavior of labor income, in the aggregate as well as across industries and education groups. We explore whether returns on financial assets are significant explanatory variables for labor income - a necessary condition for financial assets to be useful as hedges for nontraded human capital. We do find significant predictability for many categories of labor income. We also provide an overview of two approaches to computing "returns" on human capital and provide some new evidence on the statistical properties of human capital returns.

Section 10.4 provides a more detailed analysis of the benefits of a reformed social security system that allows retirees to earn returns on the basis of an optimal investment in the stock market during the retirement period. Depending on the extent of risk aversion and some other factors, we find substantial benefits to holding some type of risky asset. Further, there are additional benefits to optimal international portfolio diversification. 
Section 10.5 turns to the issue of how retirement funds should be invested during the working years. We use a simple life-cycle model to highlight the issues that are involved, particularly those concerning uncertainty about labor income (human capital returns). We illustrate how optimal portfolio construction depends on the sensitivity of labor income to the returns on financial assets. Our analysis illustrates that the importance of the risk-management motive in the overall demand for particular assets depends critically on whether the variations in income are temporary or permanent. Section 10.6 concludes.

\subsection{Social Security: An Overview}

Social Security represents a large fraction of the wealth of retirees, as shown in table 10.1. This table describes asset holdings for fifty-one-to sixty-one-year-olds, broken down by income percentiles (data are from the Health and Retirement Survey, as compiled by Gustman et al. [1997] and Gustman and Steinmeier [1998]). For the group as a whole, the value of social security represented 31 percent of other financial assets. Social security value represents a smaller fraction - about 12 percent - of other assets for individuals in the highest and lowest earnings groups. For individuals in the 10-25 percent bracket, social security value is 54 percent of other assets (these individuals have average lifetime earnings of $\$ 392,781$, or about $\$ 13,000$ per year, assuming that the individual worked from age twenty-five to age sixty-five).

Social security is also a major source of income for retired persons: the Social Security Administration reports that social security represents 40 percent of all income to the aged population and more than 50 percent of income for two-thirds of "beneficiary units" (couples or nonmarried persons). Social security was the only source of income for 18 percent of the aged population (see SSA 1989, 6).

Under many proposed reforms of social security, an element of the traditional social security system will be kept intact: individuals will be required to make "contributions" to the system, and these contributions will lead to a claim on benefits via a formula similar to the one currently in use. Viewed in finance terms, social security represents a nontraded financial asset - we say that it is nontraded because a worker who has contributed to social security and thus accumulated retirement benefits through the system cannot sell or trade this claim on social security. In this section, we explore the risk and return characteristics of this nontraded financial asset. We begin by reviewing the salient characteristics of the social security claim and then compare this claim to tradable financial assets available in the private market. 


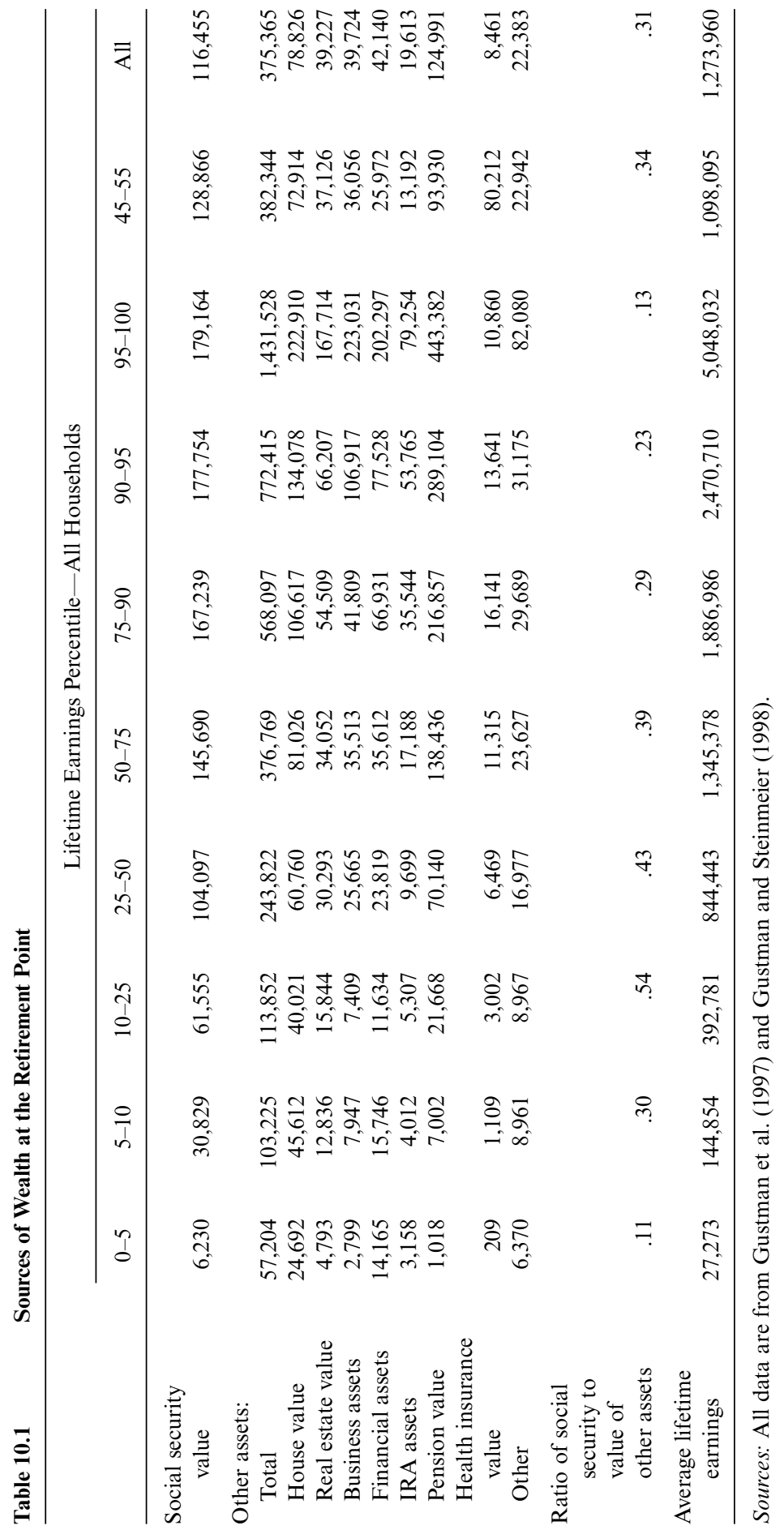




\subsubsection{Social Security Cash Flows}

It will be useful to develop notation for the different types of cash flows embedded in the social security asset. An individual begins his working life at date $t$, making nominal contributions $Z_{t+j}$ to social security; $Z_{t+j}$ includes employer contributions. These contributions continue until the individual's last period of work, period $t+R$. From retirement at date $t+R+1$ until the individual's death at date $t+T$, the social security system pays benefits $B_{t+R+j}$ to the individual. We are ignoring survivor benefits and death benefits.

\section{Working Years}

A self-employed, covered worker is required to contribute to social security an amount equal to 12.4 percent of earnings up to a cap or ceiling amount denoted $\mathrm{CAP}_{t+j^{\prime}}$. For 1999 , the cap is equal to $\$ 72,600$. Employees' social security contributions, or payments, are 6.2 percent of earnings, and these are matched by an additional 6.2 percent contribution from employers. Thus, the total contribution is

$$
Z_{t+j}=0.124 \cdot \min \left(W_{t+j}, \mathrm{CAP}_{t+j}\right), \quad j=1,2, \ldots, R,
$$

where $\min \left(W_{t+j}, \mathrm{CAP}_{t+j}\right)$ is the smaller of wage income and the ceiling amount in period $t+j .{ }^{1}$

\section{The Retirement Point and Beyond}

When an individual retires at date $t+R$, social security benefits for the retirement period are computed as follows. A worker's earnings during the preretirement years are adjusted to reflect the increase in the general level of wages during the particular working year in which the wages were earned and the retirement date. The idea behind this adjustment, or indexation, is to ensure that a retired worker's benefits reflect the rise in wages that occurred over his working life. This adjustment is carried out through the computation of the individual's "average indexed monthly earnings," or AIME. The AIME is constructed as follows. Let $\bar{W}_{t+j}$ denote the national average wage index for year $t+j$, and let $\bar{W}_{t+R}$ denote the national average wage index for the retirement year, $t+R .{ }^{2}$ The worker's indexed earnings $W_{t+j}^{\text {indexed }}$ are computed as follows:

1. The source for this OASDI tax-rate figure is http://www.ssa.gov/OACT/COLA/tax Rates.html. Since the current chapter concentrates on retirement-savings issues, we ignore the hospital insurance (HI) taxes, which are 2.9 percent of a self-employed individual's income and are not subject to a cap.

2 . The "national average wage index" computed by social security is actually a measure of average income for covered workers. As such, it is comparable to a measure of average per capita labor income, not an average wage rate. 


$$
W_{t+j}^{\text {indexed }}=W_{t+j}\left(\frac{\bar{W}_{t+R}}{\overline{W_{t+j}}}\right), \quad j=1,2, \ldots, R .
$$

The worker's average indexed monthly earnings is then the average over the individual's working life of $W_{t+j}^{\text {indexed:3 }}$

$$
\operatorname{AIME}=\frac{1}{12}\left[\frac{1}{R+1} \sum_{j=0}^{R} W_{t+j}\left(\frac{\bar{W}_{t+R}}{\overline{W_{t+j}}}\right)\right] .
$$

The individual's social security benefit, $B_{t+R+j}$, depends on the individual's AIME. Specifically, the individual's "primary insurance amount," PIA, equals 90 percent of the first $\$ 477$ of AIME plus 32 percent of AIME over $\$ 477$ through $\$ 2,875$ plus 15 percent of AIME over $\$ 2,875$. The fact that the PIA is a concave function of AIME can be interpreted as implicit taxation, or redistribution, from retirees who had high incomes over their lifetime toward retirees who had lower incomes. Let PIA ${ }_{t+R+1}$ denote the PIA for a worker who retires in period $t+R$ and begins receiving benefits in period $(t+R+1)$, expressed on an annual basis. In subsequent periods, the PIA will be adjusted for inflation so that nominal benefits are given by

$$
B_{t+R+j}=\operatorname{PIA}_{t+R+1}\left(\frac{P_{t+R+1+j}}{P_{t+R+1}}\right), \quad j=1,2, \ldots,(T-t-R-1),
$$

where $P_{t+R+1+j}$ is the CPI price index.

Social security benefits are best viewed as an annuity flow, an income received by an individual or a household so long as one or more of its members survives. This real annuity is "purchased" through social security contributions during the individual's working life. There are many private market instruments that are similar in general terms, and we turn next to discussing these instruments.

\subsubsection{Private Market Assets Similar to Social Security}

Under some proposed reforms, social security will be largely or completely privatized. For this reason, it is important to understand what private market financial instruments could be used to replace a government-run social security system. Further, if social security remains as a government-run program but is "modernized" in the sense of offering new products, it is useful to understand the similarities and differences between social security and similar, privately provided products.

In this section, we describe private market annuity products, high-

3. The AIME calculation excludes some low-wage years and years of nonemploymenta feature not captured by our formula. 
lighting the similarities and differences with the social security annuity. Annuities are technically insurance contracts and are marketed by the major insurance companies. Increasingly, however, annuity products are being offered by insurance company affiliates of the major mutual fund companies, such as Vanguard and Fidelity.

Annuities are typically described by three main attributes:

\begin{tabular}{lll}
\hline How Purchased? & Payments Begin? & Rule for Payments? \\
\hline Single premium & Immediately & Fixed (in nominal terms) \\
Flexible premium & Deferred & Variable (in nominal terms) \\
\hline
\end{tabular}

Annuities can be purchased with a single premium (a lump-sum payment at a point in time), or the annuity can be purchased via many payments over time-these are called flexible premium annuities. When purchased, the annuity delivery can be immediate (with payments to the individual starting on the day of purchase), or it can be deferred (starting at a later date). Finally, the annuity payouts can be fixed, with the nominal payment fixed over time, or it can be variable. We now describe various annuities in more detail.

\section{Fixed Annuities}

A fixed annuity specifies a sequence of known, fixed cash flows that will be received by the annuitant. Generally, the cash flows will continue (once begun) for the lifetime of the annuity owner; alternatively, the time period may be shorter and would be specified in advance of the first distribution. Private annuity markets provide fixed annuities with a variety of survivorship characteristics. Some annuities will provide benefits just for the lifetime of the annuitant; others provide survivor benefits of various kinds (see table 10.2). A "fixed" annuity is not a "real" annuity because the fixed annuity provides a guaranteed stream of fixed, nominal cash payments. Social security, by contrast, indexes the cash payments to the CPI inflation rate.

\section{Variable Annuities}

The private annuity market currently provides a broad range of investment options for variable annuities, including money market funds, a variety of bond funds, and several stock funds, including international portfolios. During the accumulation phase, the individual invests in one or more of these funds and is typically allowed to reallocate wealth across the funds with few restrictions.

The "distribution phase" of the annuity begins when the annuitant starts to take distributions, or cash flows, from the annuity. The annuity is called a deferred annuity if a period of time elapses between the accumulation and the distribution phases; the annuity is called an immediate annuity 
Table 10.2

Types of Variable Annuities Offered by Vanguard

\begin{tabular}{|c|c|c|}
\hline Payment Option & Type of Payment & How Long Payments Last \\
\hline Life annuity & Variable or fixed & $\begin{array}{l}\text { For lifetime of annuitant, even if fixed payments exceed } \\
\text { the value of the annuity contract. }\end{array}$ \\
\hline $\begin{array}{l}\text { Joint-and-last } \\
\text { survivor annuity }\end{array}$ & Variable or fixed & $\begin{array}{l}\text { For as long as either one of the two annuitants remains } \\
\text { alive, even if payments exceed the value of the } \\
\text { annuity contract. }\end{array}$ \\
\hline $\begin{array}{l}\text { Life annuity with } \\
\text { period certain }\end{array}$ & Variable or fixed & $\begin{array}{l}\text { For lifetime of annuitant, with choice of at least } 120 \text {, } \\
\text { 180, or } 240 \text { months guaranteed. Balance of } \\
\text { guaranteed payments goes to beneficiaries if } \\
\text { annuitant dies during that period. }\end{array}$ \\
\hline $\begin{array}{l}\text { Installment or } \\
\text { unit refund life } \\
\text { annuity }\end{array}$ & Variable or fixed & $\begin{array}{l}\text { For lifetime of annuitant, with guaranteed number of } \\
\text { payments based on value of annuity divided by the } \\
\text { amount of the first monthly payment. Balance of } \\
\text { guaranteed payments goes to beneficiaries if } \\
\text { annuitant dies. }\end{array}$ \\
\hline $\begin{array}{l}\text { Designated- } \\
\text { period annuity }\end{array}$ & Fixed only & $\begin{array}{l}\text { For a designated period of between ten and thirty } \\
\text { years. Balance of payments goes to beneficiaries if } \\
\text { annuitant dies during that period. }\end{array}$ \\
\hline
\end{tabular}

Source: The Vanguard Group: http://www.vanguard.com.

if the distribution phase begins immediately after the annuity is purchased. ${ }^{4}$

Owners of variable annuities have many options for how the accumulated assets are paid out. The total accumulated value can be paid out in a single lump sum, or "withdrawals" can be made at irregular intervals. Alternatively, and of the most interest for our purposes, the owner of the variable annuity can choose to annuitize his investment. The decision to annuitize is irreversible. A sample of the choices for annuitization is given in table 10.2, which describes annuitization options available to investors in Vanguard's variable-annuity products. This table shows a wide range of options that vary according to whether the payouts are fixed dollar amounts that vary each period or whether they vary according to the portfolio chosen by the investor. Further, the payout options differ in the length of time that payments are made and the extent to which payments may be transferred to a beneficiary in the event of the annuitant's death.

4. Mitchell, Poterba, and Warshawsky $(1997,5)$ analyze the "money's worth" of singlepremium, immediate annuities since it is clear that "the life annuity represents the predominant decumulation method." According to Mitchell, Poterba, and Warshawsky, "Flexible premium payments accounted for $\$ 46.6$ billion in 1995 , compared with $\$ 52.5$ billion of single premium annuity payments. Single Premium Immediate Annuities, however, accounted for only $\$ 6.2$ billion of premium payments in 1995, while Single Premium Deferred Annuities accounted for $\$ 46.3$ billion. The small volume of SPIA purchases suggests that the recent growth of the aggregate annuity market has not resolved the long-standing puzzle, discussed for example in Friedman and Warshawsky (1990), of why individuals do not choose to annuitize their wealth." 


\subsubsection{Social Security as a Variable Annuity}

Using the terminology of the private annuity markets, social security is a flexible-premium, deferred, variable annuity since the "purchases" or contributions to social security vary over time and because the payouts are deferred to the retirement period. Once payouts begin, they are variable in nominal terms owing to CPI indexation. The private annuity from table 10.2 that is closest to the social security annuity is the "joint and last survivor annuity" with fixed payments. This annuity yields fixed payments as long as either of the two annuitants is alive, which is similar to the social security provision to continue to provide benefits to surviving spouses.

Let us take a closer look at the similarities and differences between social security and private annuities. During the accumulation phase, the rate of return on the private annuity is the rate of return on the portfolio that the investor has chosen. Further, the investor in a private annuity may have the right to reallocate invested funds to alternative portfolios without cost. By contrast, the contributor to social security does not choose the investment vehicle for his contributions - social security contributions are ostensibly invested in U.S. Treasury securities. However, the rate of return on the social security "asset" during the accumulation phase is not the rate of return on U.S. Treasury securities, as will be discussed more fully in section 10.2 below. There, we argue that the rate of return is related to the rate of change of the U.S. average wage index.

Private annuities and social security also differ during the distribution phase (the retirement period). First, fixed-payment annuities offered by private firms are fixed in nominal terms, while social security payments are indexed to inflation and therefore are fixed in real terms. Second, distributions from private annuities depend proportionately on the value of the annuity investment at the annuitization point. By contrast, the formulas used by the Social Security Administration to compute the AIME and the PIA, combined with rules about the family maximum, mean that distributions from social security are not simple linear functions of the value of contributions. Third, private annuities that have survivor benefits do not condition these benefits on the income or wealth of the survivor. Social security does have conditions of this sort: a surviving spouse who has worked at a high-income job may receive no survivor benefits. This is a redistributive "estate-tax" component built into the current social security system. Finally, private annuities are legal contracts specifying cash flows (or rules for determining cash flows) and cannot be changed. ${ }^{5}$ By contrast, social security distributions can be changed by an act of Congress, adding

5. The Vanguard variable annuities have "separate-account" status, which means that the assets purchased by the annuitant are not available to the insurance company's creditors in the case of bankruptcy. 
an important element of uncertainty for participants in the social security system.

\subsection{Evaluating Social Security as a Financial Asset}

Many proposals for social security reform allow for individual choice among assets in which to invest retirement funds. Some proposals keep important elements of social security in its current form while allowing additional funds to be invested in assets of the individual's choosing. Other proposals contemplate allowing the social security trust fund to invest in a broader menu of traded financial assets. Our goal in this section is to begin to evaluate the risk-return trade-offs facing investors under the current social security system and also under systems that may be implemented in the future. We pay particular attention to the importance of the diversification benefits provided by including international assets in the investment portfolio.

\subsubsection{A First Look at Social Security Risk and Return}

This section takes a first look at the risk and return characteristics of social security during the accumulation phase. A worker who contributes $\$ 1$ to social security will have that $\$ 1$ "marked up," according to the AIME formula (1), by the rate of change of the social security wage-indexing series for each period between the contribution date and the retirement date. That is, $\$ 1$ contributed at date $t$ will grow as follows:

$\$ 1$ at date $t$ grows to

$$
\begin{aligned}
& \$ 1\left(\frac{\bar{W}_{t+1}}{\overline{W_{t}}}\right) \text { at date } t+1, \\
& \$ 1\left(\frac{\bar{W}_{t+1}}{\bar{W}_{t}}\right)\left(\frac{\bar{W}_{t+2}}{\bar{W}_{t+1}}\right) \text { at date } t+2, \\
& \$ 1\left(\frac{\bar{W}_{t+1}}{\bar{W}_{t}}\right)\left(\frac{\bar{W}_{t+2}}{\bar{W}_{t+1}}\right) \cdots\left(\frac{\bar{W}_{t+R}}{\bar{W}_{t+R-1}}\right) \text { at retirement date, } t+R .
\end{aligned}
$$

Equation (3) shows that the nominal return during the accumulation phase to $\$ 1$ "invested" in social security is the growth rate of the wageindexing series since this is the amount by which the $\$ 1$ is "marked up" each period up to the retirement date. ${ }^{6}$

6. This definition of the return to social security over the accumulation phase ignores elements of risk associated with the possibility of future changes in the rules for "marking up" contributions. 
Since many proposals for social security reform call for alternative investment vehicles for social security contributions, it is of interest to compare the risk and return characteristics of investment in the present social security system to some potential, alternative rules governing social security investments. To begin, we studied how closely the growth in the wageindexing series corresponds to a measure of per capita income growth and per capita GNP growth. The growth rates of these variables, in real terms, are shown in figure 10.1, and summary statistics are given in table 10.3. The wage index and per capita labor income are deflated using the CPI deflator; GNP is deflated using the GNP deflator. The real wage-indexing series grew at only 0.95 percent per year for the period 1951-96, while real per capita income grew at 1.65 percent per year, and per capita real GNP grew at 1.85 percent per year. The wage-indexing series is about as volatile as GNP growth, while per capita labor income is somewhat more volatile. Although per capital real income growth is highly correlated $(0.90)$ with

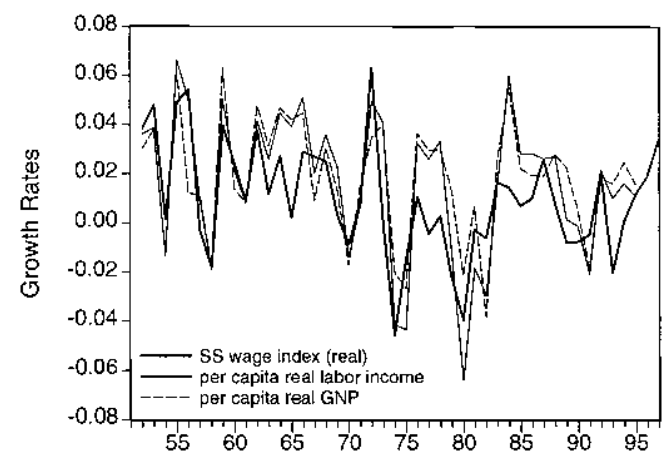

Fig. 10.1 Growth rates of real wage index, per capita labor income, and GNP

Table 10.3

Social Security Wage Index, Labor Income, and GNP, 1951-97

\begin{tabular}{lccc}
\hline & $\begin{array}{c}\text { Social Security } \\
\text { Wage Index }\end{array}$ & $\begin{array}{c}\text { Per Capita } \\
\text { Labor Income }\end{array}$ & $\begin{array}{c}\text { Per Capita } \\
\text { GNP }\end{array}$ \\
\hline Mean (\% per year) & 0.96 & Growth Rates & 1.85 \\
Standard deviation (\% per year) & 2.34 & 1.64 & 2.39 \\
& \multicolumn{4}{c}{ Correlations } \\
Social security wage index & 1.00 & 0.80 & 0.64 \\
Per capita labor income & 0.80 & 1.00 & 0.90 \\
Per capita GNP & 0.64 & 0.90 & 1.00 \\
\hline
\end{tabular}

Note: All variables are expressed in real terms. Wage index and labor income are deflated using the CPI; GNP is deflated using the GNP deflator. 
per capita real GNP growth, the growth rate of the wage index has a correlation of only 0.84 with income growth and only 0.64 with GNP growth. ${ }^{7}$

\subsubsection{Refining Our Measure of Social Security Risk and Return}

In our discussion to this point, we assumed that social security was exactly a wage-indexed variable annuity during the accumulation phase, that is, an account in which the individual's contributions bear a return equal to the rate of growth of the aggregate wage index. We found that this made social security a low-risk and low-return asset. Consequently, the typical investor would like to combine other assets with this social security asset as part of a portfolio.

Social security is actually more complicated than this wage-indexed variable annuity. To see how this richer detail could affect the calculations presented above, it is useful to begin by studying the wage-indexed variable annuity a little further. For this purpose, as above, let $Z_{t}$ be the joint contributions of the employer and the employee. Then we can describe the "wage-indexed fund account balance" by the following accumulation equation,

$$
M_{t}=\frac{\overline{W_{t}}}{\overline{W_{t-1}}} M_{t-1}+Z_{t}=\left(1+r_{t}^{w}\right) M_{t-1}+Z_{t},
$$

where the portfolio return is defined by $1+r_{t}^{w} \equiv \bar{W}_{t} / \bar{W}_{t-1}$. This expression highlights a key element of the social security system that we stressed above: the fact that social security earnings are indexed to the aggregate wage index makes the behavior of this index an important determinant of the return on the social security asset for individuals. The average rate of growth of the index affects the average level of benefits, the variability of this index over time influences the variability of benefits, and the comovement of this index with other assets can be important for portfolio composition.

However, social security is more complicated than this annuity account along several dimensions. First, at retirement, the individual does not receive $M_{R}$ dollars but rather receives an annuity. This is easily handled since it is straightforward to convert between the market value of the annuity and the market value of the account by using an annuity price. Second, the benefit formula makes the annuity payment depend, not on the individual's contributions, but instead on income history. The social security system's rules imply that accumulated lifetime earnings to date $t$, denoted $\mathrm{LE}_{t}$, evolve as

7. We were surprised that the wage-indexing series did not bear a closer relation to these measures of aggregate economic activity. To the extent that "macro markets" of the type proposed by Shiller (1993) could allow individuals to hedge aggregate risk, the current social security wage-indexing scheme appears to introduce idiosyncratic risk into the social security asset that could not be hedged with a claim on aggregate GNP. 


$$
\mathrm{LE}_{t}=\frac{\overline{W_{t}}}{\overline{W_{t-1}}} \mathrm{LE}_{t-1}+W_{t}
$$

Thus, social security benefits inherit the wage-indexed account's sensitivity to aggregate fluctuations. Further, with a fixed tax rate, there is a simple proportional relation between lifetime earnings and the wage-indexed account balance: the account balance $M_{t}$ is just the accumulated lifetime earnings $\mathrm{LE}_{t}$ multiplied by the tax rate $\tau$ :

$$
M_{t}=\tau \times \mathrm{LE}_{t} .
$$

Thus, in a situation where the tax rate is constant, there is a rescaling from the current system's rules to our stylized description of a social security account.

Third, the social security rules make marginal benefits a function of the level of accumulated lifetime earnings. Hence, there is a form of redistribution or insurance built into the system. This distinction can be very important: many studies have shown that social security implicit returns vary widely across individuals (see, e.g., Feldstein and Samwick 1992). But these modifications do not obscure the fact that our social security account balance and individuals' actual benefit payments both vary with the rate of growth of wages. ${ }^{8}$ Thus, we study the average social security return and its volatility using our "wage-indexed-annuity" approach in the next sections.

\subsubsection{Risk and Return of Traded Financial Assets}

Perhaps the most important development of postwar financial economics is the analysis of risk and return of portfolios, as in Markowitz (1959). An important building block for our analysis of the role of international investment in retirement portfolios is therefore the risk-return structure of traded financial assets. The extent to which diversification and riskmanagement benefits can be obtained by holding foreign assets depends on the correlation between returns on foreign assets and the returns on domestic assets, both traded and nontraded.

We begin by looking at the relation between U.S. and U.K. equity returns over the period 1918-96, as reported in table 10.4. The returns are annual and are expressed in real, local currency units, deflated using consumer price indices. ${ }^{9}$ Over this period, U.K. returns had higher real returns and higher volatility compared with the United States. The correlation between equity returns in the United States and the United Kingdom was 0.52 .

If the end of the Bretton-Woods system and the recent increase in open-

8. To determine the evolution of an individual's benefit payments through time, it may be necessary to scale the average return by a factor determined by the shape of the benefit function.

9. Data are from Campbell (1999). 
Table 10.4

U.S. and U.K. Equity Returns, 1918-96

\begin{tabular}{lcc}
\hline & U.S. Equity Return & U.K. Equity Return \\
\hline Mean (\% per year) & 9.41 & 10.54 \\
Standard deviation (\% per year) & 20.41 & 26.16 \\
& & Correlations \\
U.S. equity return & 1.00 & \\
U.K. equity return & 0.52 & 0.52 \\
\hline
\end{tabular}

Sources: Data are from various sources, as described by Campbell (1999).

Note: All returns are computed from real, local currency units, deflated using the consumer price index (United Kingdom) and the Gustman-Steinmeier consumption deflator (United States).

ness of financial markets means that the structure of asset returns has changed, it may be useful to focus on a shorter, more recent time period. Table 10.5 gives information on equity and bond returns for a variety of portfolios, using quarterly data from 1970:1-1998:1. Returns are real, U.S. dollar returns, deflated using the GNP deflator. The equity returns are total returns, as reported by Morgan Stanley Capital International. The bond returns are total returns on long-term government securities, published by the IMF. The "Europe" bond portfolio is an equally weighted portfolio of the United Kingdom, France, Italy, Germany, and Switzerland. The "Asia" bond portfolio is an equally weighted portfolio of Japan and Australia. The broad impression from table 10.5 is that equity and bond returns were positively correlated across countries during this period. In particular, the correlation of U.S. equity returns with other equity returns is reasonably high: 0.67 in the case of the United States-Europe and 0.43 in the case of the United States-the Far East. The correlation of U.S. equity returns with bond returns is lower, suggesting a potentially important role for U.S. and foreign bonds in a diversified portfolio.

To give an idea of the extent of the benefits from diversification among traded assets, figure 10.2 shows the "efficient frontier" for combinations of U.S. and foreign assets. The inner (dashed) line is the frontier for U.S. assets only-combinations of U.S. equities and U.S. bonds. The points with a star inside a circle are U.S. assets (bonds and equities); the open circles are foreign assets. The outer (solid) line is the frontier for U.S. and foreign assets combined. This graph indicates that diversifying internationally could be beneficial in terms of improving the risk-return trade-off for a U.S. investor.

\subsubsection{Expanding the Menu of Social Security Assets}

This section investigates the benefits of broadening the menu of assets that investors may use for their retirement savings, either as part of addon PRAs of the type proposed by Feldstein and Samwick (1997) or as part of a "modernized" social security scheme run by the government. 
Social Security and Traded Financial Assets (annual data, 1970-97)

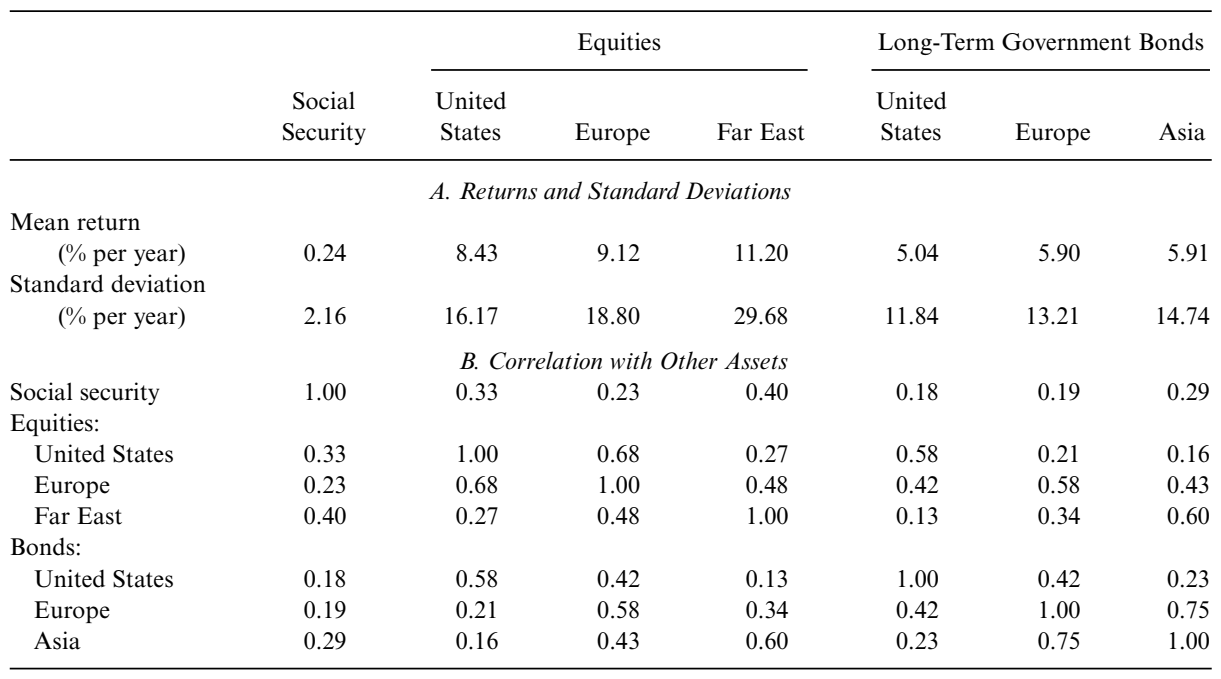

Source: Equity returns are total returns as reported by Morgan Stanley Capital International. Bond returns are total returns on long-term government bonds as reported by the IMF.

Note: The social security return is the growth rate of the wage-indexing series, deflated using the CPI. All other returns are in real U.S. dollars, deflated using the GNP deflator.

In this section, we will be focusing only on the diversification benefits obtained through a broader menu of assets; the potential for riskmanagement benefits will be considered later.

Figure 10.3 shows the risk-return trade-off that can be achieved by combining the traditional social security "asset" described earlier with other traded financial assets. This figure should be interpreted as describing the risk-return trade-off facing a worker in the accumulation phase (i.e., still saving for retirement). The statistics used to compute this trade-off are given in table 10.5. ${ }^{10}$ Social security is the asset in the lower-left-hand corner of the figure, with an average return of 0.24 percent per year and a standard deviation of 2.16 percent. As before, the dashed line represents the trade-off for investors who confine their portfolios to U.S. assets: in this case, social security plus U.S. bonds and equities. The solid line represents the trade-off for investors who invest in combinations of social security, U.S. assets, and foreign assets.

How useful are international assets to a retirement investor, through the diversification channel stressed here? The answer depends critically on several factors: the tolerance of the investor for the higher levels of risk entailed in international investments; the risk-return profile of the inves-

10. We experimented with using a longer time period, 1951-96, with only two traded securities: U.S. and U.K. equity returns (these are the only returns that we have for this longer time period). The results were qualitatively very similar to those reported in the text. 


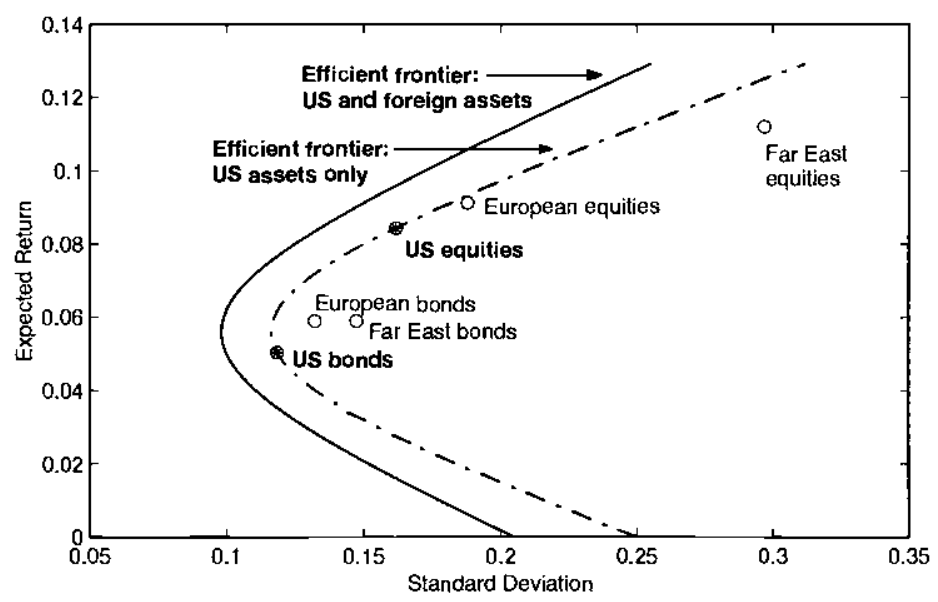

Fig. 10.2 Portfolios of traded assets

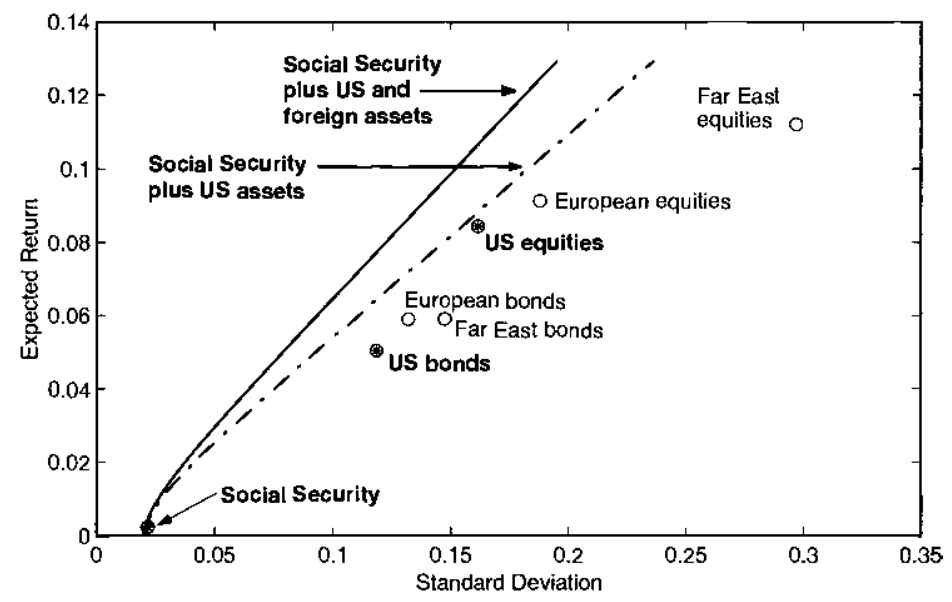

Fig. 10.3 Portfolios combining social security with other assets

tor's current portfolio; and the constraints on the investor that are due to the rules of particular retirement schemes.

Consider, for example, an investor who is invested 100 percent in the current social security system. Now imagine that this individual can undertake a small amount of investment in financial assets of his or her choice, either through PRAs or through some other scheme. How much does it matter whether this investor makes use of (or has access to) international investments? To be more concrete, suppose that the investor wants to earn an expected return of 3.00 percent per year rather than 0.25 percent per year (the return from investing 100 percent in the current 
Portfolios Combining Social Security with Other Assets

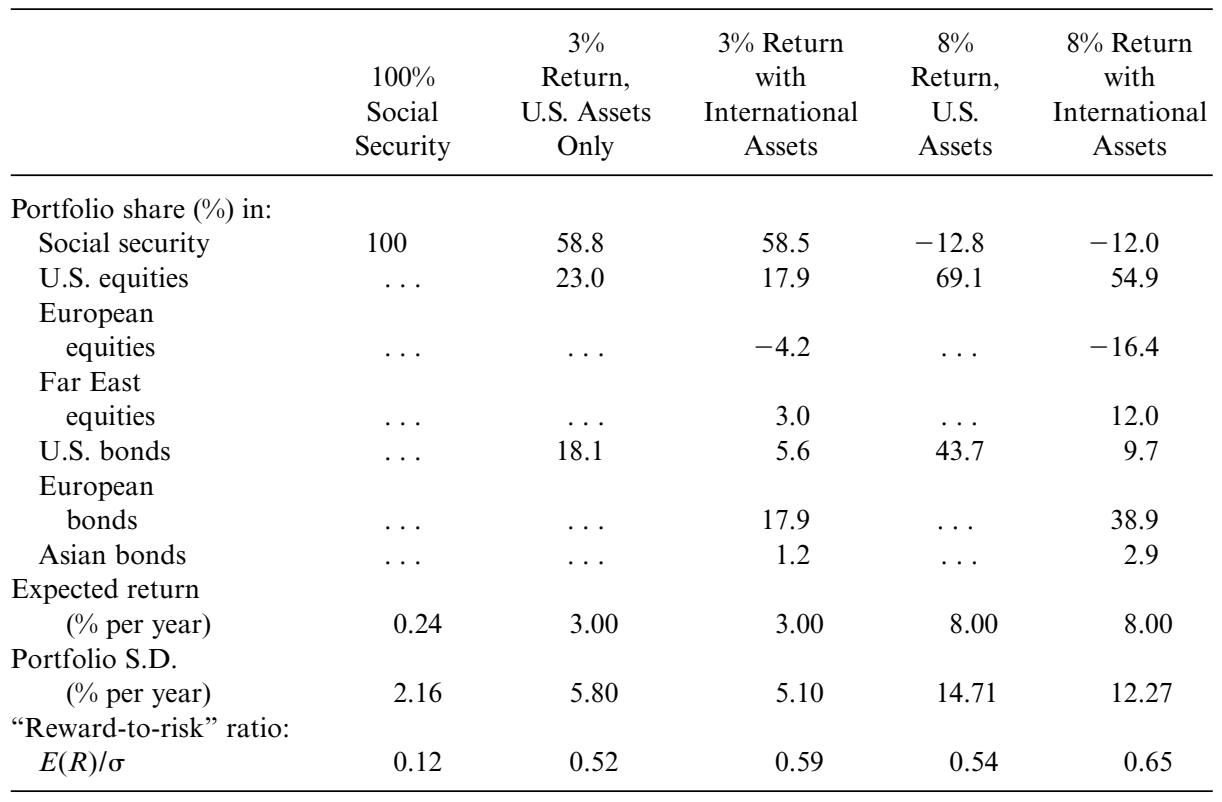

social security scheme). If the investor confines himself to social security plus U.S. assets, the portfolio shares necessary to achieve this return are as follows: 58.8 percent in social security, 23.1 percent in U.S. equities, and 18.1 percent in U.S. bonds (for more detail, see table 10.6). The standard deviation of this portfolio is 5.8 percent per year. Adding international investments reduces the standard deviation of the portfolio only slightly, to 5.1 percent per year (the portfolio fractions are as follows: social security, 58.8 percent; U.S. equities, 17.9 percent; European equities, -0.4 percent; Far Eastern equities, 0.3 percent; U.S. bonds, 0.6 percent; European bonds, 17.9 percent; and Asian bonds, 1.2 percent).

When the individual's starting point is being fully invested in the current social security scheme and the investor is contemplating only "small" increases in the risk and return of his portfolio, there are large gains to including stocks or long-term bonds in the portfolio. This situation would apply to investors who are very risk averse or are effectively risk averse because of their position in their life cycle or income level. It would also apply to investors who are constrained by the rules of a modified social security scheme that permitted only small fractions of one's investment portfolio to be invested in assets of the individual's choice. The marginal gains to international diversification are small, however, compared with investing all the risky component of one's portfolio in domestic assets.

The benefits to international diversification are more noticeable when 
the circumstances or preferences permit individuals to take on higher levels of risk in their retirement portfolios. For example, table 10.6 shows that a portfolio with an expected return of 10 percent has a standard deviation of 14.71 percent when only U.S. assets are considered as opposed to 12.27 percent when international assets are part of the portfolio. ${ }^{11}$

\subsection{Human Capital as a Nontraded Asset}

Human capital is the single most important asset for most individuals. Since labor income represents about two-thirds of GNP, human capital represents roughly two-thirds of aggregate national wealth. There will be variations across individuals: young people who have had little opportunity to save and who have most of their working lives ahead of them will have a higher fraction of total wealth in the form of human capital; retirees will have a relatively small ratio of human capital to total wealth.

Table 10.7 gives an idea of the importance of human capital relative net worth for different types of individuals. ${ }^{12}$ We computed the value of human capital by assuming a real growth rate of 2 percent per year for labor income over the individual's remaining working life and discounted future labor income at the real rate $r$. If human capital is viewed as riskless or as having only idiosyncratic risk, then it would be appropriate to use the risk-free interest rate, say, $r=0.02$, to discount future labor income. If, alternatively, human capital is about as risky as risky financial assets, then it would be more appropriate to use a discount such as $r=0.08$, approximately the average long-run return on equity. No matter which method is used to discount future labor income, table 10.7 shows that human capital is the most important single asset held by nonretired individuals. It is especially important for low-income and young individuals. Even for individuals who are near retirement, those in the fifty-five-to sixty-five-year age bracket, human capital is still the largest component of wealth.

Human capital is a risky asset because of uncertainty in labor income, which represents the flow of "dividends" from this asset. Part of the volatility of an individual's labor income may be common across all individuals, which can be characterized as "aggregate" risk. The remaining component of income volatility is individual-specific, "idiosyncratic" risk. This section looks at the characteristics of labor income volatility and the re-

11. Portfolio shares in the U.S.-only portfolio are as follows: -12.8 percent in social security (or, nearly equivalently, borrowing Treasury bills); 69.1 percent in U.S. equities; and 43.7 percent in U.S. bonds. Portfolio shares in the international portfolio are -12 percent social security, 54.8 percent U.S. equities, -16.4 percent European equities, 12.0 percent Far Eastern equities, 9.7 percent U.S. bonds, 48.9 percent European bonds, and 2.3 percent Asian bonds.

12. Friend and Blume (1975) also treat human capital as a nontraded, risky asset and use data from an earlier Survey of Consumer Finances to compute an estimate of human capital as a fraction of net worth. 


\begin{tabular}{cccccc} 
& & & & Human & Human \\
Future & & Median & 1995 & Net & $\begin{array}{c}\text { Capital/ } \\
\text { Net }\end{array}$ \\
Years & Median & 1995 & Income/ & Worth: & Worth: \\
of & 1995 & Net & Net & $r=0.02 ;$ & $r=0.08 ;$ \\
Work & Income & Worth & Worth & $g=0.02$ & $g=0.02$ \\
\hline
\end{tabular}

\begin{tabular}{|c|c|c|c|c|c|c|}
\hline \multicolumn{7}{|l|}{ Income group: } \\
\hline Less than $\$ 10,000$ & 23 & 5,000 & 4,800 & 1.0 & 23.5 & 12.7 \\
\hline$\$ 10,000-\$ 24,999$ & 23 & 17,500 & 30,000 & 0.6 & 13.2 & 7.1 \\
\hline$\$ 25,000-\$ 49,999$ & 23 & 37,500 & 54,900 & 0.7 & 15.4 & 8.3 \\
\hline$\$ 50,000-\$ 99,999$ & 23 & 75,000 & 121,100 & 0.6 & 14.0 & 7.5 \\
\hline$\$ 100,000$ and more & 23 & 200,000 & 485,900 & 0.4 & 9.3 & 5.0 \\
\hline \multicolumn{7}{|l|}{ Age of head: } \\
\hline Under 35 & 37 & 26,700 & 11,400 & 2.3 & 85.0 & 34.3 \\
\hline $35-44$ & 25 & 39,100 & 48,500 & 0.8 & 19.8 & 10.2 \\
\hline $45-54$ & 15 & 41,100 & 90,500 & 0.5 & 6.7 & 4.4 \\
\hline $55-65$ & 5 & 36,000 & 110,800 & 0.3 & 1.6 & 1.3 \\
\hline $65-74$ & 1 & 19,500 & 104,100 & 0.2 & 0.2 & 0.2 \\
\hline 75 and more & 0 & 17,300 & 95,100 & 0.2 & 0.0 & 0.0 \\
\hline \multicolumn{7}{|l|}{ Education of head: } \\
\hline \multicolumn{7}{|l|}{ No high school } \\
\hline \multicolumn{7}{|l|}{ High school } \\
\hline diploma & 23 & 26,700 & 50,000 & 0.5 & 12.0 & 6.5 \\
\hline Some college & 23 & 29,800 & 43,200 & 0.7 & 15.6 & 8.4 \\
\hline College degree & 23 & 46,300 & 104,100 & 0.4 & 10.0 & 5.4 \\
\hline \multicolumn{7}{|l|}{$\begin{array}{l}\text { Race or ethnicity of } \\
\text { head: }\end{array}$} \\
\hline \multicolumn{7}{|l|}{ White non- } \\
\hline Hispanic & 23 & 48,600 & 73,900 & 0.7 & 14.8 & 8.0 \\
\hline \multicolumn{7}{|l|}{ Nonwhite or } \\
\hline Hispanic & 23 & 29,500 & 16,500 & 1.8 & 40.3 & 21.8 \\
\hline \multicolumn{7}{|l|}{$\begin{array}{l}\text { Current work status } \\
\text { of head: }\end{array}$} \\
\hline $\begin{array}{l}\text { Professional, } \\
\text { managerial }\end{array}$ & 23 & 72,700 & 89,300 & 0.8 & 18.4 & 9.9 \\
\hline $\begin{array}{l}\text { Technical, sales, } \\
\text { clerical }\end{array}$ & 23 & 46,200 & 43,300 & 1.1 & 24.1 & 13.0 \\
\hline Precision & & & & & & \\
\hline production & 23 & 43,800 & 43,500 & 1.0 & 22.7 & 12.3 \\
\hline $\begin{array}{l}\text { Machine } \\
\text { operators }\end{array}$ & & & & & & \\
\hline and laborers & 23 & 35,600 & 37,300 & 1.0 & 21.5 & 11.6 \\
\hline Service & & & & & & \\
\hline occupations & 23 & 27,200 & 15,800 & 1.7 & 38.8 & 21.0 \\
\hline Self-employed & 23 & 79,000 & 152,900 & 0.5 & 11.7 & 6.3 \\
\hline Retired & 0 & 27,300 & 81,600 & 0.3 & 0.0 & 0.0 \\
\hline Other not working & 23 & 19,900 & 4,500 & 4.4 & 99.7 & 53.9 \\
\hline
\end{tabular}

(continued) 
Table 10.7

(continued)

Source: All data are from the 1995 Survey of Consumer Finances, as summarized in Kennickell, StarrMcCluer, and Sunden (1997).

Note: Number of years of remaining working life generally assumed to be 23 (midpoint of working from age 20 to age 65). In the case of age groups, the number of years for an individual at the midpoint of the age group is used.

Median income for the "income-group" breakdown is the midpoint of the range, except for the highest group (more than $\$ 100,000$ ), for which we have arbitrarily used the figure $\$ 200,000$ as the median.

To calculate the ratio of the value of human capital to net worth, we capitalized current income over the individual's remaining working life assuming that real income rises at the rate $g$ and using a real discount rate of $r$. This calculation assumes that current income consists of wage income only, which may not be a good assumption for higher-income individuals. However, this error will bias upward the human capital/net worth ratio for individuals with high net worth and thus high levels of nonwage income, thus reducing the disparity between high- and low-wage groups.

turns to human capital. Because human capital is a nontraded asset, it is necessary to compute synthetic returns on this asset by combining observable data on labor income and other variables with an asset-pricing model. This section reviews prior studies that have used alternative methods for computing these synthetic returns and provides some new results. Next, we investigate how the nontradability of human capital affects portfolio composition. Intuitively, traded financial assets with returns that are highly correlated with human capital returns can be used to hedge human capital risk. We evaluate the extent to which domestic as opposed to international assets may be useful as hedging tools.

\subsubsection{Labor Income Volatility}

As an initial measure of the risk associated with human capital, we can look at the volatility of labor income and its relation to the business cycle. If labor income followed a simple random walk, then the return to human capital is simply the growth rate of labor income. The data do not support the random-walk model for human capital, but we begin by looking at the raw volatility of labor income growth.

\section{Aggregate Labor Income}

We begin by looking at a measure of aggregate labor income. ${ }^{13}$ As we saw in figure 10.1 above, the growth rates of real GNP and real labor income move together quite closely. In prior work, Baxter and Jermann (1997) studied data from the United States and three other OECD countries and found that one cannot reject the hypothesis that aggregate labor income is cointegrated with GNP with a cointegrating vector of [1-1] (implying that labor's share is stationary). Because aggregate labor income

13. Our measure of aggregate labor income is computed as the sum of compensation of employees (Citibase code GCOMP) and proprietor's income (GPROJ), deflated using the GNP deflator (GD). 
moves so closely with aggregate GNP, a claim to aggregate labor income in the United States is almost the same thing as a claim on aggregate GNP. Although the "macro markets" proposed by Shiller (1993) do not (yet) exist, it is useful to note that a market in GNP could provide a useful hedging vehicle for the risk associated with aggregate labor income.

\section{Labor Income at the Industry Level}

This section looks at the properties of labor income at the industry level. We are interested in learning how the volatility of labor income and its relation to the business cycle differ across industries. We gathered data on unemployment rates, $u_{j t}$, hourly wage rates, $w_{j t}$, and hours worked per employed person, $h_{j t}$, for nine manufacturing industries indexed by $j=1$, $2, \ldots, 9$. We wanted a measure of the earnings that would be received in an industry in a particular period, taking into account the possibility of being unemployed. Thus, we computed a measure of the "unemploymentcorrected" total earnings in industry $j$ as follows:

$$
\text { earnings }_{j t}=\left(1-u_{j t}\right) w_{j t} h_{j t} \text {. }
$$

Table 10.8 shows how the mean growth rate of real earnings and its volatility differ across industries; the growth rate of real GNP is included for comparison. ${ }^{14}$ Panel A shows that there is a great deal of cross-industry variability in the behavior of unemployment-corrected labor income growth. In each of these manufacturing industries, the mean growth rate of wages is lower than the mean growth rate of GNP. Only two industries - services and wholesale trade - had wage growth that was less volatile than GNP growth. Most industries had wage growth that was substantially more volatile than GNP growth-more than twice as volatile for construction and mining.

To get an idea of the cyclic sensitivity of wages in these industries, we ran a regression of wage growth on GNP growth and have reported the coefficient on GNP growth together with the $R^{2}$ of this regression. ${ }^{15}$ The "beta" coefficient gives an idea of the cyclic sensitivity of wage growth to GNP growth; we intend the terminology to suggest an individual stock's "beta" with respect to a market index. If there were a market claim on GNP, this beta would help determine the loading on GNP in the hedge portfolio for that category of labor income. The $R^{2}$ of the regression indicates how much of the volatility of wage growth in a particular industry

14. We have used the GNP deflator for wages instead of the CPI because we are interested in comparing the behavior of real earnings with real GNP. Conceptual problems with the CPI deflator, combined with the fact that the ratio of the CPI to the GNP deflator exhibits a significant upward trend over our sample, with at least one significant "jump" around 1980 , led us to use the same deflator for all variables.

15. For most industries, adding further lags of GNP growth did not increase the adjusted $R^{2}$ of the regression. 


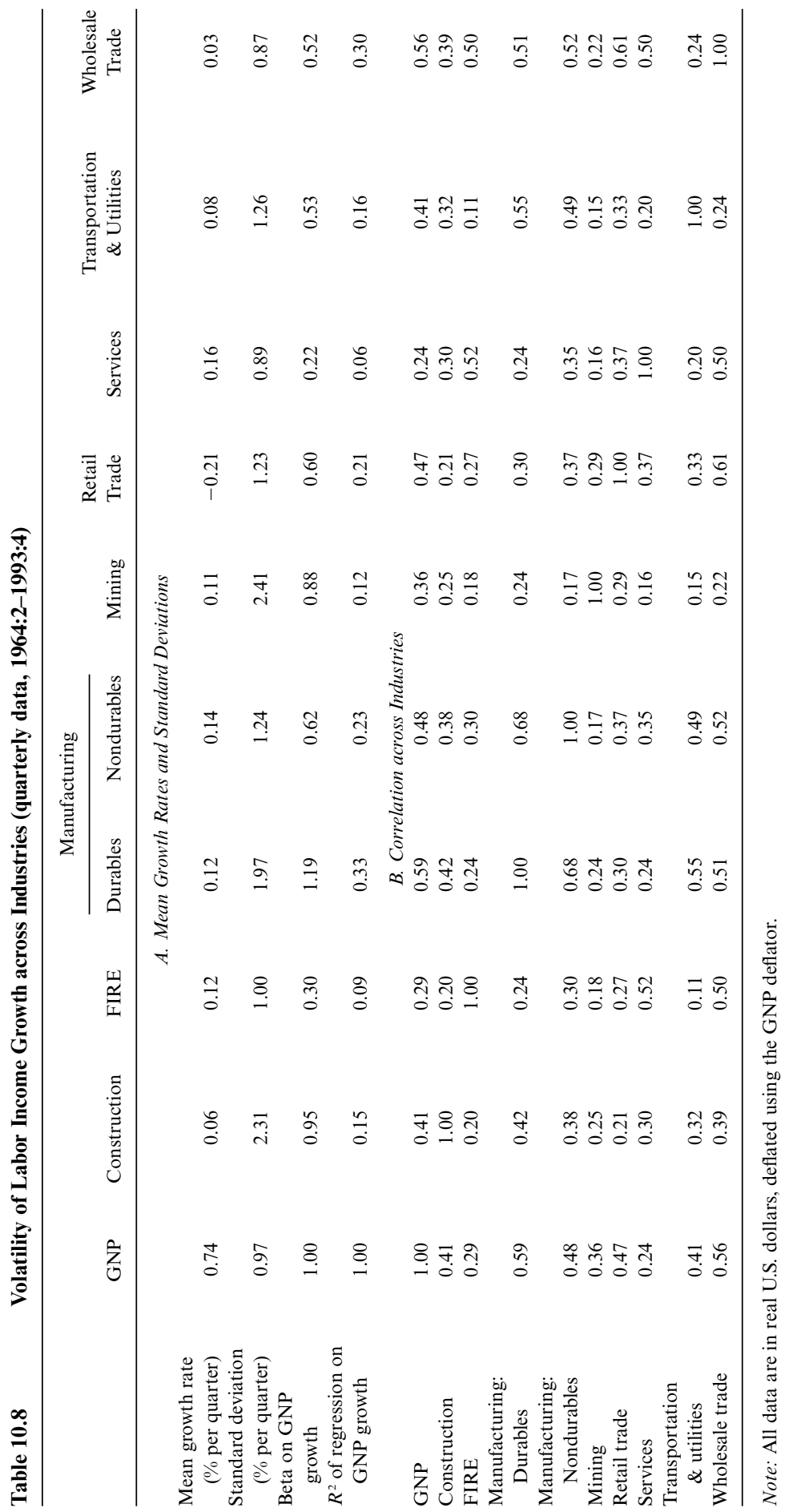


represents "aggregate risk," where we take aggregate risk to mean the risk associated with aggregate movements in GNP or changes in aggregate wages, which we have seen are nearly the same thing.

Table 10.8 shows that the manufacturing industries differ widely in their sensitivity to GNP changes, with estimated betas ranging from a low of 0.22 for services to coefficients close to 1.0 for construction, durables manufacturing, and mining. The $R^{2}$ 's for these regressions are rather low, indicating that most of the volatility in labor income growth in these industries is idiosyncratic. An implication is that human capital risk for workers in these industries would not be hedged very well with a claim on GNP.

\section{Labor Income by Education Group}

It is likely that the risk-return characteristics of human capital differ across income groups. Campbell, Cocco, Gomes, and Maenhout (chap. 11 in this volume) have constructed information on income by education group that will allow us to investigate this hypothesis. They specify a model of income for individual $i$ at date $t$ of the form ${ }^{16}$

$$
\log Y_{i t}=f\left(t, Z_{i t}\right)+v_{i t}+\varepsilon_{i t},
$$

where $f\left(t, Z_{i t}\right)$ depends on age and other individual characteristics $Z_{i t}, v_{i t}$ follows a random walk with innovation $u_{i t}$, and $\varepsilon_{i t}$ is a temporary shock. Letting $\hat{f}\left(t, Z_{i t}\right)$ denote the fitted value of $f\left(t, Z_{i t}\right)$, Campbell et al. define

$$
\log Y_{i t}^{*}=\log Y_{i t}-\hat{f}\left(t, Z_{i t}\right)
$$

which effectively purges income of fluctuations due to age or other identifiable demographic characteristics.

Campbell et al. generously provided annual data from 1971 to 1992 on the average value of $Y_{j t}^{*}$ for individuals within education group $j$. There are three such groups: never finished high school; finished high school; and additional education beyond the high school level. Table 10.9 shows the standard deviation of the growth rates of the $Y_{i t}^{*}\left(\Delta Y_{i t}^{*}\right)$ and their sensitivity to GNP growth. The standard deviation of $\Delta Y_{i t}^{*}$ for the group that never finished high school (group 1) is nearly twice the standard deviation of GNP growth, whereas the highest education group has $\Delta Y_{i t}^{*}$ about as volatile as GNP growth. In terms of correlations, $\Delta Y_{i t}^{*}$ is highly correlated with GNP growth for the lowest education group, with a correlation of 0.83 ; for the middle education group, the correlation is 0.71 , but it is only 0.33 for the group with the highest education level. The last line in the table shows the beta in a regression on GNP growth similar to the one run for the industry groups above, together with the $R^{2}$ 's for these regressions.

16. The following uses the notation of Campbell et al., not the notation of the present paper. 
Table 10.9

Volatility of Labor Income Growth across Education Groups (annual data, 1971-96)

\begin{tabular}{lccc}
\hline & $\begin{array}{c}\text { Less Than } \\
\text { High School }\end{array}$ & $\begin{array}{c}\text { Finished } \\
\text { High School }\end{array}$ & $\begin{array}{c}\text { More Than } \\
\text { High School }\end{array}$ \\
\hline \multicolumn{3}{c}{$\begin{array}{c}\text { A. Mean } \\
\text { Srowth Rates and } \\
\text { Mean growth rate (\% per year) }\end{array}$} & \multicolumn{3}{c}{ atard Deviations } \\
Standard deviation (\% per year) & -0.06 & 0.03 & 0.02 \\
Beta on GNP growth & 5.23 & 3.22 & 2.58 \\
$R^{2}$ of regression on GNP growth & 1.63 & 0.86 & 0.32 \\
& 0.68 & 0.50 & 0.11 \\
Less than high school & B. Correlation across Education & Groups \\
Finished high school & 1.00 & 0.63 & 0.20 \\
More than high school & 0.63 & 1.00 & 0.60 \\
\hline
\end{tabular}

${ }^{a}$ Mean growth rate computed from labor income growth purged of age and other demographic effects.

The lowest education group has a large value of beta at 1.63 , while the highest education group has a beta of only 0.32 . Further, the $R^{2}$ is 0.68 for the lowest education group but only 0.11 for the group with the most education. These results suggest that there are important differences across education groups in the extent of aggregate as opposed to idiosyncratic risk in labor income and thus the extent to which claims on aggregate output could be used to hedge this risk. Specifically, the lowest education group seems to be the most exposed to aggregate risk, while the highest education group seems to be the least exposed.

\subsubsection{Hedging Human Capital Risk}

This section explores issues associated with hedging human capital risk. While we have documented that labor income is volatile, implying that human capital is risky, it remains to be seen whether existing financial assets could be useful in hedging this risk. Financial assets will be useful as hedges against human capital risk if they have significant predictive power for current and future labor income growth. This subsection explores whether such predictive power can be found in the data. ${ }^{17}$

Our results on the predictability of labor income growth using financial asset returns are summarized in table 10.10 . We consider a variety of measures of labor income and several different possibilities for traded financial assets. In panel A, we consider aggregate, per capita labor income as our measure of the flow of "dividends" from human capital; the traded finan-

17. Davis and Willen (1998) also address the question of the benefits of using financial assets to hedge human capital. 
$\Delta \log y_{t}=c+\beta \Delta \log y_{t-1}+\Gamma_{\mathrm{US}}(L) r_{t}^{\mathrm{US}}+\Gamma_{\mathrm{UK}}(L) r_{t}^{\mathrm{UK}}+\varepsilon_{t}$

\begin{tabular}{|c|c|c|c|c|c|c|}
\hline & \multirow[b]{2}{*}{$\begin{array}{c}\beta \\
\text { (S.E.) }\end{array}$} & \multicolumn{2}{|c|}{$\begin{array}{l}\text { Sum of Coefficients } \\
\text { in } \Gamma(L) \\
\text { ( } p \text {-value for } F \text {-test } \\
\text { that sum is zero) }\end{array}$} & \multirow{2}{*}{$\begin{array}{c}\text { Far } \\
\text { East } \\
\text { Equities }\end{array}$} & \multirow{2}{*}{$\begin{array}{c}R^{2}, \\
\text { Regression } \\
\text { with } \\
\Delta \log y_{t-1} \\
\text { Only }\end{array}$} & \multirow{2}{*}{$\begin{array}{c}R^{2}, \\
\text { Regression } \\
\text { with } \\
\text { Equity } \\
\text { Returns }\end{array}$} \\
\hline & & $\begin{array}{l}\text { U.S. } \\
\text { Equities }\end{array}$ & $\begin{array}{l}\text { U.K. } \\
\text { Equities }\end{array}$ & & & \\
\hline \multicolumn{7}{|c|}{ A. Results for Aggregate Labor Income per Capita and Social Security (annual data, 1951-97)a } \\
\hline $\begin{array}{l}\text { Aggregate real labor } \\
\text { income (per capita) }\end{array}$ & $\begin{array}{l}.489 \\
(.113)\end{array}$ & $\begin{array}{l}.06 \\
(.07)\end{array}$ & $\begin{array}{l}.06 \\
(.00)\end{array}$ & & .080 & .477 \\
\hline $\begin{array}{l}\text { Social security (rate of } \\
\text { growth of aggregate } \\
\text { wage index }\end{array}$ & $\begin{array}{l}.315 \\
(.131)\end{array}$ & $\begin{array}{l}.06 \\
(.07)\end{array}$ & $\begin{array}{l}.03 \\
(.12)\end{array}$ & & .078 & .430 \\
\hline \multicolumn{7}{|c|}{ B. Results for Aggregate Labor Income (quarterly data, 1969:4-1998:1)b } \\
\hline $\begin{array}{l}\text { Aggregate real labor } \\
\text { income }\end{array}$ & $\begin{array}{l}.445 \\
(.087)\end{array}$ & $\begin{array}{l}.05 \\
(.07)\end{array}$ & $\begin{array}{l}.03 \\
(.97)\end{array}$ & $\begin{array}{l}.03 \\
(.01)\end{array}$ & .326 & .541 \\
\hline \multicolumn{7}{|c|}{ C. Results for Nine Manufacturing Industries (quarterly data, 1969:4-1998:1) ${ }^{\mathrm{C}}$} \\
\hline Construction & $\begin{array}{l}.060 \\
(.098)\end{array}$ & $\begin{array}{l}.13 \\
(.08)\end{array}$ & $\begin{array}{l}-.06 \\
(.38)\end{array}$ & $\begin{array}{l}.06 \\
(.09)\end{array}$ & .006 & .166 \\
\hline FIRE & $\begin{array}{l}.064 \\
(.115)\end{array}$ & $\begin{array}{l}.01 \\
(.85)\end{array}$ & $\begin{array}{l}.00 \\
(.31)\end{array}$ & $\begin{array}{l}.02 \\
(.31)\end{array}$ & .006 & .111 \\
\hline $\begin{array}{l}\text { Manufacturing: } \\
\text { durables }\end{array}$ & $\begin{array}{l}.170 \\
(.098)\end{array}$ & $\begin{array}{l}.14 \\
(.02)\end{array}$ & $\begin{array}{l}-.05 \\
(.41)\end{array}$ & $\begin{array}{l}.06 \\
(.45)\end{array}$ & .081 & .309 \\
\hline $\begin{array}{c}\text { Manufacturing: } \\
\text { nondurables }\end{array}$ & $\begin{array}{l}.104 \\
(.098)\end{array}$ & $\begin{array}{l}.13 \\
(.00)\end{array}$ & $\begin{array}{r}-.02 \\
(.60)\end{array}$ & $\begin{array}{l}.03 \\
(.12)\end{array}$ & .042 & .34 \\
\hline Mining & $\begin{array}{r}-.092 \\
(.099)\end{array}$ & $\begin{array}{l}.03 \\
(.67)\end{array}$ & $\begin{array}{l}.03 \\
(.69)\end{array}$ & $\begin{array}{l}.03 \\
(.45)\end{array}$ & .023 & .129 \\
\hline Retail trade & $\begin{array}{l}-.104 \\
(.101)\end{array}$ & $\begin{array}{l}.10 \\
(.02)\end{array}$ & $\begin{array}{r}-.00 \\
(.94)\end{array}$ & $\begin{array}{l}.01 \\
(.56)\end{array}$ & .000 & .211 \\
\hline Services & $\begin{array}{l}.053 \\
(.108)\end{array}$ & $\begin{array}{l}.04 \\
(.13)\end{array}$ & $\begin{array}{l}-.01 \\
(.77)\end{array}$ & $\begin{array}{l}.02 \\
(.19)\end{array}$ & .000 & .182 \\
\hline $\begin{array}{l}\text { Transportation \& } \\
\text { utilities }\end{array}$ & $\begin{array}{r}-.010 \\
(.101)\end{array}$ & $\begin{array}{l}.07 \\
(.07)\end{array}$ & $\begin{array}{c}-.01 \\
(.78)\end{array}$ & $\begin{array}{l}.02 \\
(.36)\end{array}$ & .002 & .217 \\
\hline Wholesale trade & $\begin{array}{l}.169 \\
(.100)\end{array}$ & $\begin{array}{l}.06 \\
(.03)\end{array}$ & $\begin{array}{l}-.00 \\
(.89)\end{array}$ & $\begin{array}{l}.01 \\
(.37)\end{array}$ & .038 & .207 \\
\hline \multicolumn{7}{|c|}{ D. Results for Different Educational Groups (annual data, 1971-96) ${ }^{\mathrm{d}}$} \\
\hline Less than high school & $\begin{array}{l}-.276 \\
(.285)\end{array}$ & $\begin{array}{l}.00 \\
(.99)\end{array}$ & $\begin{array}{l}.12 \\
(.60)\end{array}$ & $\begin{array}{l}.01 \\
(.91)\end{array}$ & .186 & .290 \\
\hline Finished high school & $\begin{array}{c}.323 \\
(.339)\end{array}$ & $\begin{array}{l}.12 \\
(.25)\end{array}$ & $\begin{array}{r}-.08 \\
(.50)\end{array}$ & $\begin{array}{l}.05 \\
(.36)\end{array}$ & .076 & .342 \\
\hline More than high school & $\begin{array}{r}-.027 \\
(.274)\end{array}$ & $\begin{array}{l}.02 \\
(.74)\end{array}$ & $\begin{array}{l}.07 \\
(.42)\end{array}$ & $\begin{array}{l}.01 \\
(.90)\end{array}$ & .013 & .439 \\
\hline
\end{tabular}

a Polynomials $\Gamma(L)$ contain lags 0 and 1 .

b Polynomials $\Gamma(L)$ contain lags $0-4$.

'Polynomials $\Gamma(L)$ contain lags $0-3$.

dPolynomials $\Gamma(L)$ contain lags 0 and 1 . 
cial assets that we consider are U.S. and U.K. equities. Our data are annual, covering the period 1951-98. We ran a regression of the form

$$
\Delta \log y_{t}=c+\beta \Delta \log y_{t-1}+\Gamma_{\mathrm{US}}(L) r_{t}^{\mathrm{US}}+\Gamma_{\mathrm{UK}}(L) r_{t}^{\mathrm{UK}}+\varepsilon_{t},
$$

where we included lags 0 and 1 in the polynomials $\Gamma_{\mathrm{US}}(L)$ and $\Gamma_{\mathrm{UK}}(L)$. We found that U.S. and U.K. equities each had significant predictive power for aggregate, per capita labor income growth. This suggests an important role for both U.S. and U.K. equities in hedging human capital risk, where the measure of human capital is aggregate labor income. For an individual, this result could be interpreted as implying that U.S. and U.K. equities could be useful in hedging the aggregate component of his human capital risk.

The last row of panel A runs a similar regression for the "social security asset" - the rate of growth of the wage-indexing series. Here, we find that U.S. equities but not U.K. equities are useful predictors for the growth rate of the wage-indexing series.

Panel B of table 10.10 looks at the predictability of aggregate labor income (not per capita) when the traded assets include U.S. equities, European equities, and Far East equities. The sample is quarterly, 1969:41998:1. Again, we find an important role for U.S. equities in hedging aggregate human capital risk. European equities are not significant predictors of aggregate labor income growth, but Far East equities are strongly significant. At least over this time period, then, U.S. and Far East (mainly Japanese) equities would have provided useful hedges for aggregate human capital.

Panel C of table 10.10 looks at the predictability of labor income growth in nine industries, using the same quarterly data set for financial variables. We find that the U.S. equity return is a significant predictor of labor income growth in six of the nine industries, while European and Far East equities are never significant. The strongest results are for those industries known for their cyclic sensitivity: construction and the manufacturing industries. Our results imply that U.S. equities could provide a useful hedge for human capital risk in several industries.

Finally, panel D looks at the predictability of labor income growth for the education groups described above. We find no equity return that is a significant predictor of labor income growth, although including the equity returns in the regressions does increase the fit of the regressions substantially.

Overall, our findings suggest that returns on financial assets, notably U.S. equities, are significant predictors of labor income growth. These results suggest an important role for U.S. equities in hedging the risk of nontraded human capital. Specifically, an individual whose labor income growth is positively correlated with U.S. equity returns would hedge by 
holding a reduced fraction of his portfolio of traded financial assets in the form of U.S. equities. As a consequence, the individual's holdings of foreign assets or risk-free assets would necessarily be increased.

\subsubsection{Computing Human Capital Returns: Literature Review}

Since human capital is a nontraded asset, measuring human capital returns requires an asset-pricing model that links observable cash flows from human capital to returns on this asset. This section summarizes alternative approaches that have been used in the literature.

\section{The Approach of Campbell}

Campbell (1996) constructs a multifactor model of asset returns in which risky human capital plays an important role. By assuming that the conditional expected return on human capital is equal to the conditional expected return on financial wealth, Campbell derives the following expression for the return on human capital:

$$
\text { (4) } r_{y, t+1}-E_{t} r_{y, t+1}=\left(E_{t+1}-E_{t}\right) \sum_{j=0}^{\infty} \rho^{j} \Delta y_{t+1+j}-\left(E_{t+1}-E_{t}\right) \sum_{j=0}^{\infty} \rho^{j} r_{a, t+1+j} \text {, }
$$

where $r_{y, t+1}$ is the return on human capital, $\Delta y_{t+1+j}$ is the growth rate of labor income, $r_{a, t+1+j}$ is the return on financial assets, and $\rho$ is a discount factor. Thus, human capital returns are high when there are upward revisions in expected future labor income growth but low when expected future returns on financial assets are high because the given stream of labor income is discounted at a higher rate. Campbell finds that there is important predictability of future labor income growth using current and lagged labor income growth and that, in monthly data at least, financial market variables also help predict labor income growth. Campbell also finds that most of the variability in the return on human capital is accounted for by the variance of the "discount rate news" term, $\left(E_{t+1}-E_{t}\right) \sum_{j=0}^{\infty} \rho^{j} r_{a, t+1+j}$. Specifically, the variance of the human capital return in monthly data is reported as 20.8 (percent per month), while the variance of the labor income news is only 1.256. Thus, the correlation between human capital returns and returns on financial assets is necessarily quite high: 0.94 for the monthly data and 0.54 for the annual data. ${ }^{18}$

\section{The Approach of Baxter and Jermann}

Baxter and Jermann (1997) use a somewhat different approach, working with a version of (4) in which expected returns on financial assets are

18. In earlier work, Fama and Schwert (1977) study human capital returns in a version of (4) that assumed that labor income growth could not be forecast and where there was assumed to be no variation in expected future discount rates. These alternative assumptions explain why Fama and Schwert found little relation between human capital returns and returns on financial assets. 
constant. The starting point for the Baxter-Jermann work is the observation that labor's share of GNP appears to be stationary so that labor income and capital income are cointegrated. They specify a vector error correction model (VECM) for labor income growth and capital income growth as follows:

$$
\begin{aligned}
\Delta d_{L, t+1}= & \delta_{L}+\beta_{L}(L) \Delta d_{L t}+\gamma_{L}(L) \Delta d_{K t} \\
& +\alpha_{L}\left(d_{L t}-d_{K t}\right)+\varepsilon_{L, t+1}, \\
\Delta d_{K, t+1}= & \delta_{K}+\beta_{K}(L) \Delta d_{L t}+\gamma_{K}(L) \Delta d_{K t} \\
& +\alpha_{K}\left(d_{L t}-d_{K t}\right)+\varepsilon_{K, t+1},
\end{aligned}
$$

where $d_{L t}$ denotes the log of labor income, $d_{K t}$ denotes the log of capital income, $\Delta d_{L, t+1} \equiv d_{L, t+1}-d_{L t}, \Delta d_{K, t+1} \equiv d_{K, t+1}-d_{K t}$, and $\beta_{L}(L), \beta_{K}(L)$, $\gamma_{L}(L)$, and $\gamma_{K}\left({ }_{L}\right)$ are polynomials in the lag operator, $L$. Returns to labor and capital were then computed as follows:

$$
\begin{aligned}
& r_{t, t+1}^{L}-E\left(r_{t, t+1}^{L}\right)=\left(E_{t+1}-E_{t}\right)\left(\sum_{j=0}^{\infty} \rho^{j} \Delta d_{L, t+1+j}\right), \\
& r_{t, t+1}^{K}-E\left(r_{t, t+1}^{K}\right)=\left(E_{t+1}-E_{t}\right)\left(\sum_{j=0}^{\infty} \rho^{j} \Delta d_{K, t+1+j}\right) .
\end{aligned}
$$

Because labor and capital income share a common stochastic trend, and because returns on an asset are dominated by revisions in the expected trend component, labor and capital returns were found to be very highly correlated, with the correlation exceeding 0.92 for the United States, Japan, and Germany and a correlation of 0.78 for the United Kingdom. If the return on physical capital is best proxied by the return on the unlevered stock market, as argued by Black (1987), then these results suggest a high correlation between human capital returns and returns on the domestic stock market.

\section{Returns on Human Capital: Some New Evidence}

This section uses a version of the approach of Shiller (1993) and Baxter and Jermann (1997) to compute U.S. aggregate human capital returns where the "dividend" flow is aggregate U.S. labor income. This approach is distinct from Campbell's because it assumes that the discount rate is constant. Thus, all variation in returns is due to changes in expected future dividend flows.

We want to explore how useful domestic and foreign assets may be in hedging human capital risk. Intuitively, traded financial assets are useful as hedges for human capital risk if they have returns that are highly correlated with human capital returns. Further, traded financial assets are im- 
portant determinants of the returns on human capital to the extent that returns on financial assets help predict future growth in labor income. Thus, we estimated a process for income of the form

$$
\begin{aligned}
\Delta \log y_{t}= & c+\Gamma_{Y}(L) \Delta \log y_{t-1}+\Gamma_{\mathrm{US}}(L) r_{t}^{\mathrm{US}} \\
& +\Gamma_{\text {foreign }}(L) r_{t}^{\text {foreign }}+\varepsilon_{t}
\end{aligned}
$$

and computed returns on human capital using the formula

$$
r_{t, t+1}^{Y}-E\left(r_{t, t+1}^{Y}\right)=\left(E_{t+1}-E_{t}\right)\left(\sum_{j=0}^{\infty} \rho^{j} \Delta y_{t+1+j}\right) .
$$

Table 10.11 contains information on the return characteristics of various measures of labor income. The structure of table 10.11 parallels that of table 10.10 above in terms of the measure of labor income considered and the menu of financial assets. In each case, we report results for several choices of lag length in the polynomials $\Gamma_{j}(L)$ since the choice of lag length significantly affects our results in some cases.

Panel A has results for per capita labor income. The standard deviation of the returns on this measure of human capital is about .04 (4 percent per year) — about one-third as volatile as U.S. equities. Our results indicate that human capital returns are strongly correlated with U.S. equity returns and with U.K. equity returns as well; there is some evidence that the correlation with the U.S. equity return is stronger. The results for the social security asset are similar, except that the social security returns are uniformly more correlated with U.S. equity returns than with U.K. returns.

Panel B contains results for quarterly aggregate labor income and three equity portfolios. We find that this measure of aggregate human capital returns is positively correlated with U.S. equity returns as well as being positively correlated with European and Far East equity returns. There is no clear evidence on which financial asset is most highly correlated with human capital; the results are sensitive to the lag length in the VAR for labor income growth.

Panel C contains results for human capital by industry. In general, human capital returns at the industry are positively correlated with U.S. and foreign equities. The results are quite sensitive to lag length, however, and it is difficult to draw clear conclusions from this table. It appears that those industries that we identified earlier as "cyclically sensitive" — construction and the manufacturing of durables and nondurables - are the industries with the highest correlation with U.S. equity returns. However, we also estimate high correlation between human capital returns and U.S. equity returns in the wholesale and retail trade industries. Finally, panel D contains results for the three education groups. The results here are quite sensitive to lag length, and the correlations are in some cases negative. Our 


\begin{tabular}{|c|c|c|c|c|c|}
\hline & \multirow{2}{*}{$\begin{array}{c}\text { No. of } \\
\text { Lags in } \\
\text { VAR }\end{array}$} & \multirow{2}{*}{$\begin{array}{l}\text { S.D. of } \\
\text { Human } \\
\text { Capital } \\
\text { Return }\end{array}$} & \multicolumn{3}{|c|}{$\begin{array}{l}\text { Correlation between Human Capital } \\
\text { Return and Equity Return }\end{array}$} \\
\hline & & & $\begin{array}{c}\text { U.S. } \\
\text { Equities }\end{array}$ & $\begin{array}{c}\text { U.K. } \\
\text { Equities }\end{array}$ & $\begin{array}{l}\text { Far East } \\
\text { Equities }\end{array}$ \\
\hline \multicolumn{6}{|c|}{ A. Results for Aggregate Labor Income per Capita and Social Security (annual data, 1951-97) } \\
\hline \multirow{4}{*}{$\begin{array}{l}\text { Aggregate real labor income } \\
\text { (per capita) }\end{array}$} & 1 & .0434 & .68 & .71 & \\
\hline & 2 & .0369 & .55 & .50 & \\
\hline & 3 & .0359 & .71 & .45 & \\
\hline & 4 & .0254 & .54 & .34 & \\
\hline \multirow{4}{*}{$\begin{array}{l}\text { Social security (rate of growth } \\
\text { of aggregate wage index) }\end{array}$} & 1 & .0309 & .65 & .64 & \\
\hline & 2 & .0267 & .63 & .50 & \\
\hline & 3 & .0343 & .75 & .64 & \\
\hline & 4 & .0318 & .61 & .57 & \\
\hline \multicolumn{6}{|c|}{ B. Results for Aggregate Labor Income (quarterly data, 1969:4-1998:1) } \\
\hline \multirow{4}{*}{ Aggregate real labor income } & 1 & .0157 & .12 & .23 & .33 \\
\hline & 2 & .0158 & .38 & .52 & .50 \\
\hline & 3 & .0181 & .49 & .52 & .54 \\
\hline & 4 & .0162 & .60 & .56 & .63 \\
\hline \multicolumn{6}{|c|}{ C. Results for Nine Manufacturing Industries (quarterly data, 1969:4-1998:1) } \\
\hline \multirow[t]{4}{*}{ Construction } & 1 & .0304 & .18 & .13 & .25 \\
\hline & 2 & .0215 & .23 & .26 & .39 \\
\hline & 3 & .0255 & .52 & .34 & .49 \\
\hline & 4 & .0354 & .64 & .36 & .53 \\
\hline \multirow[t]{4}{*}{ FIRE } & 1 & .0126 & .42 & .40 & .38 \\
\hline & 2 & .0109 & .37 & .46 & .41 \\
\hline & 3 & .0136 & .32 & .33 & .37 \\
\hline & 4 & .0158 & .42 & .33 & .30 \\
\hline \multirow[t]{4}{*}{ Manufacturing: durables } & 1 & .0287 & .25 & .24 & .28 \\
\hline & 2 & .0252 & .46 & .39 & .49 \\
\hline & 3 & .0281 & .60 & .39 & .51 \\
\hline & 4 & .0248 & .56 & .37 & .47 \\
\hline \multirow[t]{4}{*}{ Manufacturing: nondurables } & 1 & .0181 & .45 & .42 & .38 \\
\hline & 2 & .0164 & .62 & .50 & .47 \\
\hline & 3 & .0187 & .72 & .52 & .51 \\
\hline & 4 & .0178 & .69 & .55 & .49 \\
\hline \multirow[t]{4}{*}{ Mining } & 1 & .0213 & .11 & .19 & .20 \\
\hline & 2 & .0216 & .12 & .17 & .30 \\
\hline & 3 & .0215 & .29 & .27 & .36 \\
\hline & 4 & .0212 & .36 & .25 & .42 \\
\hline \multirow[t]{4}{*}{ Retail trade } & 1 & .0118 & .38 & .46 & .43 \\
\hline & 2 & .0168 & .58 & .49 & .44 \\
\hline & 3 & .0171 & .63 & .45 & .41 \\
\hline & 4 & .0213 & .63 & .41 & .43 \\
\hline \multirow[t]{4}{*}{ Services } & 1 & .0120 & .21 & .30 & .31 \\
\hline & 2 & .0103 & .35 & .42 & .45 \\
\hline & 3 & .0112 & .59 & .48 & .57 \\
\hline & 4 & .0207 & .57 & .34 & .37 \\
\hline \multirow[t]{4}{*}{ Transportation \& utilities } & 1 & .0156 & .18 & .19 & .20 \\
\hline & 2 & .0150 & .37 & .33 & .40 \\
\hline & 3 & .0174 & .49 & .33 & .38 \\
\hline & 4 & .0227 & .43 & .32 & .18 \\
\hline \multirow[t]{4}{*}{ Wholesale trade } & 1 & .0124 & .39 & .36 & .38 \\
\hline & 2 & .0134 & .47 & .38 & .40 \\
\hline & 3 & .0149 & .56 & .39 & .42 \\
\hline & 4 & .0172 & .56 & .32 & .39 \\
\hline
\end{tabular}




\begin{tabular}{|c|c|c|c|c|c|}
\hline & \multirow{2}{*}{$\begin{array}{c}\text { No. of } \\
\text { Lags in } \\
\text { VAR }\end{array}$} & \multirow{2}{*}{$\begin{array}{l}\text { S.D. of } \\
\text { Human } \\
\text { Capital } \\
\text { Return }\end{array}$} & \multicolumn{3}{|c|}{$\begin{array}{l}\text { Correlation between Human Capital } \\
\text { Return and Equity Return }\end{array}$} \\
\hline & & & $\begin{array}{l}\text { U.S. } \\
\text { Equities }\end{array}$ & $\begin{array}{l}\text { U.K. } \\
\text { Equities }\end{array}$ & $\begin{array}{l}\text { Far East } \\
\text { Equities }\end{array}$ \\
\hline \multicolumn{6}{|c|}{ D. Results for Different Education Groups (annual data, 1971-96) } \\
\hline \multirow[t]{2}{*}{ Less than high school } & 1 & .0424 & .22 & .33 & .30 \\
\hline & 2 & .0458 & -.17 & -.14 & -.04 \\
\hline \multirow[t]{2}{*}{ High school } & 1 & .0429 & .43 & .35 & .43 \\
\hline & 2 & .0267 & .16 & .25 & .28 \\
\hline \multirow[t]{2}{*}{ More than high school } & 1 & .0293 & .50 & .61 & .41 \\
\hline & 2 & .0236 & .56 & .35 & .54 \\
\hline
\end{tabular}

interpretation is that the very short sample period (twenty-four years, annual data) is insufficient to estimate (9) with any precision.

\subsection{Quantifying the Benefits of Social Security Reform to Retirees}

Under social security, individuals receive a certain real annuity with spousal survival rights. By contrast, in the private variable-annuities market, individuals can receive annuity payments that depend on the returns on risky portfolios. Thus, one direction for social security reform is to expand the menu of annuities available to social security participants during the retirement period. For example, individuals might choose a certain real annuity, as under the current plan, or they might choose a risky portfolio whose return depended on the domestic or international stock markets. Further, they might choose some of each.

In this section, we provide a detailed analysis of the benefits to social security reform that would accrue to retirees if they were free to choose the nature of the annuity payment that they would receive, with a specific focus on the benefits from investment in international risky assets. We work with a basic model designed to highlight the issues. We also discuss the implications of extending the model in various directions. The discussion focuses on a household that is at retirement age, which we view as exogenously determined and denote as $R$ as above, and that can live until a maximum age $T$. We use a utility-based model because we are interested in learning about the determinants of the demand for risky assets as a fraction of wealth, the fraction of this demand that is for international assets, the likelihood that short-sales constraints bind, and the cost of restrictions on the composition of the portfolio.

\subsubsection{Preferences}

We assume that households have time-separable preferences and that momentary utility is 


$$
u\left(c_{t}, \underline{c}_{t}\right)=\frac{1}{1-\sigma}\left[\left(c_{t}-\underline{c}_{t}\right)^{1-\sigma}\right] .
$$

According to this expression, individuals derive utility from the deviation of the level of consumption, $c_{t}$, from a mandated level of consumption, $\underline{c}_{t}$. We have written utility in this form for several reasons. First, it allows for a "subsistence" level of consumption, $\underline{c}_{t}$, the importance of which is frequently discussed in public policy discussions of social security and other transfer programs. Second, the inclusion of $\underline{c}_{t}$ may be viewed as representing "habitual" levels of consumption that are built up over the prior work years (in this latter interpretation, we might wish to include additional terms in the utility function to represent the utility benefits from these levels). In either case, the parameter $\sigma$ governs risk aversion (higher values of $\sigma$ correspond to higher relative risk aversion) and intertemporal substitution (higher values of $\sigma$ correspond to a lower elasticity of intertemporal substitution).

We consider a group of individuals who are at the retirement point, age $R$, at calendar date $t$. We assume that individuals have a subjective discount factor $\beta$. Further, individuals have a probability $\pi_{j}$ of living for $j$ periods after retirement, and they discount future utility flows accordingly. Thus, at the retirement point, expected utility is

$$
E_{t}\left\{\sum_{j=0}^{T-R} \pi_{j} \beta^{j} u\left(c_{t+j}, \underline{c}_{t+j}\right)\right\} .
$$

\subsubsection{Retirement Portfolios with a Certain Lifetime}

The initial focus of our discussion is on optimal portfolio construction when the life span, denoted by $T$, is known with certainty. Each period, the individual begins with a level of wealth, $a$, and must choose how much to save. The individual must also decide how to allocate his portfolio: we call the fractions allocated into different assets $x_{b}, x_{d}, x_{i}$, with the subscript indicating the short-term bond $(b)$, the domestic risky asset $(d)$, or the international risky asset $(i)$. With a certain lifetime, the individual maximizes expected utility over the retirement period:

$$
E_{t}\left\{\sum_{j=0}^{\bar{T}-R} \beta^{j} u\left(c_{t+j}, \underline{c}_{t+j}\right)\right\} .
$$

Letting $b_{t}$ denote social security benefits, asset evolution can be described with the following three equations:

$$
\begin{gathered}
a_{t+1}=\left[x_{b t}\left(1+r_{b, t+1}\right)+x_{d t}\left(1+r_{d, t+1}\right)+x_{i t}\left(1+r_{i, t+1}\right)\right] f_{t}, \\
1=\left[x_{b t}+x_{d t}+x_{i t}\right], \\
c_{t}+f_{t}=a_{t}+b_{t} .
\end{gathered}
$$


Equation (12) states that the future wealth level is determined by saving, $f_{t}$, and portfolio shares and portfolio returns, through the term $\left[x_{b t}(1+\right.$ $\left.\left.r_{b, t+1}\right)+x_{d t}\left(1+r_{d, t+1}\right)+x_{i t}\left(1+r_{i, t+1}\right)\right]$. Equation (13) defines the restriction on the portfolio shares, and equation (14) is the constraint on consumption and accumulation. The individual holds a portfolio with the return

$$
1+\tilde{r}_{t+1}=\left[x_{b t}\left(1+r_{b, t+1}\right)+x_{d t}\left(1+r_{d, t+1}\right)+x_{i t}\left(1+r_{i, t+1}\right)\right] .
$$

Equivalently, this portfolio return is $1+\tilde{r}_{t+1}=\left[\left(1+r_{b, t+1}\right)+x_{d t}\left(r_{d, t+1}-\right.\right.$ $\left.\left.r_{b, t+1}\right)+x_{i t}\left(r_{i, t+1}-r_{b, t+1}\right)\right]$ when we impose the requirement (13) that the portfolio shares sum to one.

\section{Basic Results from Financial Economics}

This portfolio problem has been much studied in finance (see, e.g., Levhari and Srinvasan 1969; Samuelson 1969; and Hakansson 1970) under the assumption that there are no social security payments and no subsistence-consumption levels. We begin by summarizing the key results of this literature. One is that the marginal propensity to consume out of wealth depends on the length of the remaining lifetime and the distribution of returns but not on the level of wealth. Another result is that the portfolio shares $x$ are independent of the level of wealth and the length of the lifetime. We draw on these ideas in our discussion below and in our computation of the welfare benefits to individuals.

In general, these key results derive from studying the mathematical conditions that describe the household's optimal consumption-investment decisions. Optimal saving over time requires that

$$
D u\left(c_{t}\right)=E_{t}\left\{\left(1+\tilde{r}_{t+1}\right) D u\left(c_{t+1}\right)\right\},
$$

that is, that the marginal cost of forgoing consumption today is equated to the expected benefit of more wealth and consumption in the future. In addition, the household requires

$$
\begin{aligned}
& E_{t}\left\{\left(r_{d, t+1}-r_{b, t+1}\right) D u\left(c_{t+1}\right)\right\}=0, \\
& E_{t}\left\{\left(r_{i, t+1}-r_{b, t+1}\right) D u\left(c_{t+1}\right)\right\}=0 .
\end{aligned}
$$

That is, the retiree investor needs to make sure that the benefits from investing in particular risky assets are worth the opportunity cost of investing in the risk-free bond.

\section{The Value Functions}

In a dynamic programming analysis of the optimal consumption and investment decision, the value functions play a key role. These functions express the utility that an individual of a particular age $(R+1, R+2$, ...) receives if consumption and investment are undertaken optimally. 
To write these compactly, we let $\gamma_{t}$ denote the household's age at date $t$. Then the value function for this household, with asset holdings $a_{t}$, is given by

$$
V\left(a_{t}, \gamma_{t}\right)=\max _{c_{t}, x_{t}}\left\{u\left(c_{t}\right)+\beta E_{t} V\left(a_{t+1}, \gamma_{t+1}\right)\right\},
$$

where the maximization is undertaken subject to the constraints (12)-(14). One can show that the value functions for this retirement problem take the form

$$
v(a, \gamma)=(1-\sigma)^{-1} q(\gamma)^{1-\sigma} a^{1-\sigma},
$$

where $q(\gamma)$ embeds information on the portfolio return earned by individuals. ${ }^{19}$

\section{Nontraded Risk-Free Assets or Subsistence Consumption}

One standard extension of this basic model has been to treat the individual as having a known endowment of a nontraded asset. In our context, this could be known transfer payments that the individual expects to receive (e.g., social security benefits). This nontraded stream of income that will be received with certainty is equivalent to a (positive) endowment of bonds. In this circumstance, the bond quantities chosen in the analysis presented above must be corrected for the endowment of the bond-like nontraded asset. A nonstochastic subsistence level can be analyzed in much the same manner, except that there is a negative endowment of

19. The algebra is as follows. First, use the optimal saving condition to show that there is a marginal propensity to consume out of wealth, $\mu(\gamma)$, which satisfies

$$
\mu(\gamma)^{-\sigma}=\beta E(1+\tilde{r})^{1-\sigma} \mu\left(\gamma^{\prime}\right)^{-\sigma}[1-\mu(\gamma)]^{-\sigma},
$$

where $\mu\left(\gamma^{\prime}\right)$ is the marginal propensity to consume of an individual one period older. Second, conjecture

$$
v(a, \gamma)=q(\gamma)^{1-\sigma}\left\{\frac{1}{1-\sigma} a^{1-\sigma}\right\}
$$

so that the value recursion, together with the optimal consumption decision $c(a, \gamma)=$ $\mu(\gamma) a$, implies

$$
\begin{aligned}
v(a, \gamma) & =\left\{\frac{1}{1-\sigma}[\mu(\gamma) a]^{1-\sigma}\right\}+\beta E v\left(a^{\prime}, \gamma^{\prime}\right) \\
& =\left\{\frac{1}{1-\sigma}[\mu(\gamma) a]^{1-\sigma}\right\}+\beta q\left(\gamma^{\prime}\right)^{1-\sigma} E\left\{\frac{1}{1-\sigma}\left(a^{\prime}\right)^{1-\sigma}\right\} \\
& =\left\{\frac{1}{1-\sigma}[\mu(\gamma) a]^{1-\sigma}\right\}+\beta q\left(\gamma^{\prime}\right)^{1-\sigma} E\left\{((1+\tilde{r})(1-\mu(\gamma)) a)^{1-\sigma}\right\} .
\end{aligned}
$$

Then, the conjecture is correct is the following coefficient recursion is satisfied:

$$
q(\gamma)^{1-\sigma}=\left[\mu(\gamma)^{1-\sigma}+(1-\mu(\gamma))^{1-\sigma} E\left\{\beta(1+\tilde{r})^{1-\sigma} q\left(\gamma^{\prime}\right)^{1-\sigma}\right\} .\right.
$$


bonds from this source: the individual is required to be able to finance subsistence consumption before anything else (otherwise, he faces infinitely negative utility).

Taking both these features together, and calling the nontraded asset's income stream $\underline{b}$, the analysis presented above would then apply (at the retirement date) to a modified wealth measure,

$$
\hat{a}_{t}=\left[a_{t}+\sum_{j=0}^{T-R}\left(\frac{1}{1+r_{b}}\right)^{j}\left(\underline{b}_{t+j}-\underline{c}_{t+j}\right)\right] .
$$

That is, the individual's modified wealth measure $\hat{a}_{t}$ includes measured financial wealth plus the present value of the nontraded asset's income stream less the present value of the mandated consumption level. This modified wealth measure would be allocated into risky assets and bonds proportionately as described previously so that the individual's net demand for bonds at date $t$ would be

$$
\sum_{j=0}^{T-R}\left(\frac{1}{1+r_{b}}\right)^{j}\left(\underline{c}_{t+j}-\underline{b}_{t+j}\right)+x_{b} \hat{a}_{t} .
$$

Thus, there would be the proportional demand for bonds discussed earlier, $x_{b} \hat{a}_{t}$, plus some additional bond purchases necessary to cover the excess of required (subsistence) consumption over the income from the nontraded asset. Endowing individuals with a claim to social security payments is equivalent to endowing them with a bond. This would therefore reduce individuals' demand for other bonds, leading to a redistribution of private portfolios away from bonds and toward other risky assets that pay higher rates of return.

\subsubsection{Results for Specific Portfolio Opportunities}

What retirement portfolios would individuals choose if their investment opportunities were described by the recent risk and return characteristics of traded financial assets? In this section, we use the analytic framework that we just discussed to determine how individuals would structure their retirement portfolios given their degree of risk aversion, $\sigma$, and some specific domestic and foreign portfolios.

We use the U.S. stock market as the domestic asset and consider four different definitions of the international portfolio (returns on U.K. stocks, returns on a world portfolio composed of 50 percent European and 50 percent Far East stocks, and then the European and Far East stocks in isolation). Our results are summarized in table 10.12: this table shows how portfolio choice depends on risk aversion and on the specific foreign portfolio under consideration. 


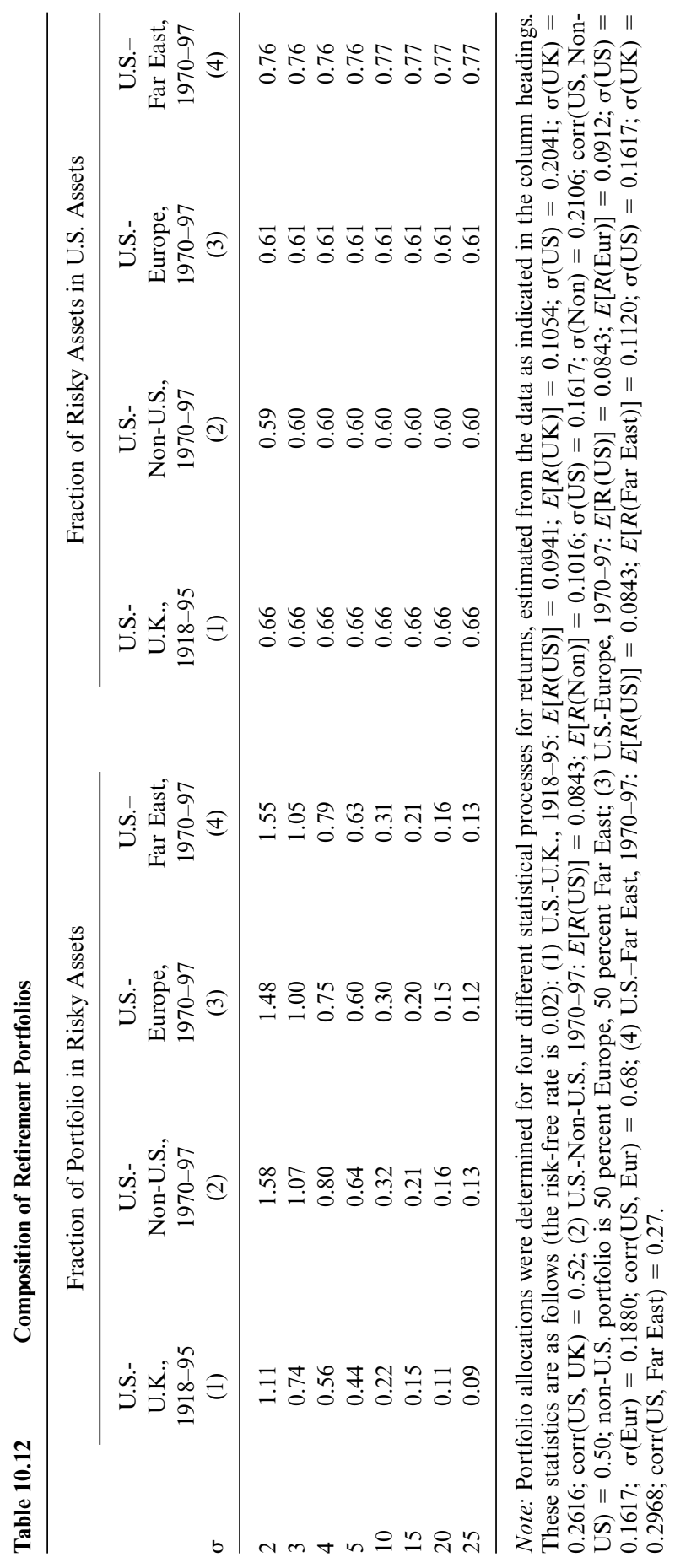


The extent of risk aversion has a major effect on the extent to which individuals invest in stocks. When risk aversion is low, with $\sigma=2$, individuals want to hold about 150 percent of their retirement portfolio in the form of risky domestic and foreign assets; they would have to borrow at the risk-free rate in order to accomplish this. As the degree of risk aversion rises, the share of the retirement portfolio invested in risky assets falls: when $\sigma=5$, the share of risky assets is about 60 percent, falling to about 20 percent for $\sigma=15$.

The share of risky assets in the retirement portfolio is not very sensitive to the choice of the international portfolio. The share of the risky portfolio invested in U.S. assets is between 66 and 77 percent, depending on the particular international portfolio under consideration. Our results indicate that the U.S. share in total risky assets is quite insensitive to the level of risk aversion. ${ }^{20}$

Overall, these results indicate that retired individuals will generally prefer to hold a retirement portfolio that is risky, in contrast to the riskless real benefit stream that comes from the current social security system. That is, they would prefer to have a portfolio including a mix of domestic and international assets along with some safe assets.

\section{Welfare Gains from Including Equities during Retirement}

The prior subsection showed that there was an important role for risky assets in individuals' retirement portfolios, for all but extremely risk-averse individuals. The current social security system is set up so that the portfolio held by a retired person is essentially a real, risk-free bond. It is natural to ask how much better off individuals would be if their retirement portfolios instead contained risky assets. Of course, the answer will depend on the length of the retirement horizon and the individual's degree of risk aversion.

To answer this question, we proceed as follows. Let $a^{b}$ denote the asset holdings of a retired person who invests all his assets in the risk-free bond. An individual of age $\gamma$ with assets $a^{b}$ invested only in bonds has value function

$$
v\left(a^{b}, \gamma\right)=(1-\sigma)^{-1} q^{b}(\gamma)^{1-\sigma}\left(a^{b}\right)^{1-\sigma}
$$

Now consider an individual who invests in equities and bonds to maximize expected retirement-period utility. Let $a^{e}$ denote this individual's wealth; at age $\gamma$, the value function of this individual is then

$$
v\left(a^{e}, \gamma\right)=(1-\sigma)^{-1} q^{e}(\gamma)^{1-\sigma}\left(a^{e}\right)^{1-\sigma}
$$

20. This result is related to the standard result of the Markowitz model augmented with a risk-free asset: all investors hold the same risky portfolio, but investors with different levels of risk aversion hold different mixes of the risky and risk-free assets. 
We set the value functions implied by the two portfolio strategies equal to each other, $v\left(a^{b}, \gamma\right)=v\left(a^{e}, \gamma\right)$, and then ask what wealth levels $a^{b}$ and $a^{e}$ are implied by this equality. It is intuitive that higher wealth levels will be needed to deliver a specific level of retirement-period utility (as summarized by the value function) when the individual is constrained to hold only the risk-free bond. Specifically, $v^{b}=v^{e}$ implies $a^{b} q^{b}=a^{e} q^{e}$. Allowing an individual to move from a bond-only portfolio to his optimal bond/ stock portfolio is equivalent to giving the individual an increase in wealth, in percentage terms, equal to $100 \times\left[\left(q^{e} / q^{b}\right)-1\right]$.

Table 10.13 reports the welfare gains from allowing individuals to move from a bond-only portfolio to the optimal portfolio, as measured by the effective increase in individual wealth. We display the effective increase in wealth for various levels of risk aversion, various lengths of the retirement period, and four different specifications of the available risky assets. The greatest gain in welfare from allowing risky investment naturally occurs for investors with low risk aversion and long retirement periods. For this group, the increase in effective wealth from allowing risky investment ranges from 55 to 75 percent. However, we find that there are notable increases in effective wealth even for investors with higher risk aversion or

Table 10.13 Welfare Gains from Risky Investment during Retirement

\begin{tabular}{|c|c|c|c|c|c|c|c|c|}
\hline \multirow[b]{2}{*}{$\sigma$} & \multicolumn{4}{|c|}{ Duration of Retirement Period } & \multicolumn{4}{|c|}{ Duration of Retirement Period } \\
\hline & 5 & 10 & 15 & 25 & 5 & 10 & 15 & 25 \\
\hline & \multicolumn{4}{|c|}{$\begin{array}{l}\text { Foreign Asset Is U.K. Equities, } \\
\qquad 1918-95\end{array}$} & \multicolumn{4}{|c|}{$\begin{array}{l}\text { Foreign Asset Is Non-U.S. Equities, } \\
\qquad 1970-97\end{array}$} \\
\hline 2 & 8.48 & 19.53 & 31.02 & 55.00 & 11.36 & 26.51 & 42.62 & 77.18 \\
\hline 3 & 5.58 & 12.64 & 19.78 & 34.10 & 7.48 & 17.09 & 26.93 & 47.02 \\
\hline 4 & 4.15 & 9.34 & 14.52 & 24.74 & 5.56 & 12.60 & 19.69 & 33.85 \\
\hline 5 & 3.30 & 7.41 & 11.47 & 19.42 & 4.43 & 9.98 & 15.52 & 26.45 \\
\hline 10 & 1.63 & 3.64 & 5.60 & 9.37 & 2.19 & 4.89 & 7.54 & 12.65 \\
\hline 15 & 1.09 & 2.41 & 3.70 & 6.17 & 1.46 & 3.24 & 4.98 & 8.31 \\
\hline 20 & 0.81 & 1.80 & 2.77 & 4.60 & 1.09 & 2.42 & 3.71 & 6.19 \\
\hline \multirow[t]{2}{*}{20} & 0.65 & 1.44 & 2.21 & 3.67 & 0.87 & 1.93 & 2.96 & 4.93 \\
\hline & \multicolumn{4}{|c|}{$\begin{array}{l}\text { Foreign Asset Is European Equities, } \\
\qquad 1970-97\end{array}$} & \multicolumn{4}{|c|}{$\begin{array}{l}\text { Foreign Asset Is Far East Equities, } \\
\qquad 1970-97\end{array}$} \\
\hline 2 & 9.95 & 23.08 & 36.88 & 66.11 & 11.09 & 25.85 & 41.51 & 75.03 \\
\hline 3 & 6.55 & 14.92 & 23.44 & 40.67 & 7.30 & 16.68 & 26.27 & 45.82 \\
\hline 4 & 4.88 & 11.02 & 17.18 & 29.41 & 5.44 & 12.31 & 19.22 & 33.02 \\
\hline 5 & 3.89 & 8.74 & 13.56 & 23.04 & 4.33 & 9.75 & 15.15 & 25.82 \\
\hline 10 & 1.92 & 4.29 & 6.61 & 11.07 & 2.14 & 4.78 & 7.36 & 12.36 \\
\hline 15 & 1.28 & 2.84 & 4.37 & 7.29 & 1.42 & 3.16 & 4.86 & 8.12 \\
\hline 20 & 0.96 & 2.13 & 3.26 & 5.43 & 1.06 & 2.37 & 3.63 & 6.05 \\
\hline 25 & 0.76 & 1.70 & 2.60 & 4.33 & 0.85 & 1.89 & 2.90 & 4.82 \\
\hline
\end{tabular}


shorter horizons. The increase in effective wealth drops below 5 percent only when the retirement horizon is less than ten years or when risk aversion exceeds $\sigma=10$. An increase in retirement wealth between 5 and 75 percent would certainly be considered economically important by most households. We therefore conclude that there are sizable benefits to including risky assets in the retirement portfolios of most individuals. ${ }^{21}$

\section{Welfare Costs of Portfolio Restrictions}

Many proposals for social security reform call for investors to have the opportunity to invest in risky assets. These proposals differ, however, in their recommendations concerning the menu of risky assets available to individuals. The Feldstein and Samwick (1997) proposal, for example, calls for individuals to invest in a diversified portfolio of U.S. assets. The Kotlikoff and Sachs (1998) proposal, on the other hand, calls for retirement funds to be invested in a diversified world portfolio. This subsection investigates the welfare implications of restricting investors to holding only U.S. assets in the risky part of their retirement portfolio. We also rule out short sales of all assets, including the risk-free bond.

Table 10.14 shows how these restrictions affect the welfare of the retired investor. We begin by noting that the "no-short-sales" constraint does not bind except for the least risk-averse investors $(\sigma=2)$. Panel A shows that the fraction of the portfolio invested in risky securities falls when investors are constrained to hold only U.S. securities: the $\sigma=3$ investor reduces his risky holdings from 105 to 93 percent of his assets; the $\sigma=10$ investor reduces risky holdings from 31 to 28 percent of assets.

The reduction in welfare from the portfolio restrictions is shown in table 10.14 , panel B. The good news from this table is that allowing individuals to invest only in U.S. equities (as well as bonds) would deliver substantial welfare gains to retired individuals, relative to a situation in which retirees are required to hold just a risk-free bond. The bad news is that restricting the portfolio to only U.S. assets means that individuals receive only about 80 percent of the welfare increase that could be gained by permitting international diversification. These results reinforce the impression from figure 10.3 above, which showed great improvements in the risk-return trade-off from combining traditional social security with U.S. bonds and equities. It was unclear from that figure how important adding international investments might be in terms of generating increased welfare; this analysis suggests that the marginal contribution to individual welfare from international investment could be quite important to a retired individual.

21. Remember that these welfare gains apply only to allowing a specified asset pool to be invested in risky assets at the retirement point. This computation does not consider the potential for risky investment during the working years to deliver a larger value for the individual's assets at the retirement point. 
A. Effects on Portfolio Shares

\begin{tabular}{|c|c|c|c|}
\hline \multirow[b]{2}{*}{$\sigma$} & \multicolumn{2}{|c|}{ Unconstrained } & \multirow{2}{*}{$\begin{array}{c}\text { Constrained } \\
\text { Fraction of } \\
\text { Portfolio in U.S. } \\
\text { Risky Assets }\end{array}$} \\
\hline & $\begin{array}{l}\text { Fraction of } \\
\text { Portfolio in } \\
\text { Risky Asset }\end{array}$ & $\begin{array}{c}\text { U.S. as } \\
\text { Fraction of } \\
\text { Risky Assets }\end{array}$ & \\
\hline 2 & 1.55 & 0.76 & 1.00 \\
\hline 3 & 1.05 & 0.76 & 0.93 \\
\hline 4 & 0.79 & 0.76 & 0.70 \\
\hline 5 & 0.63 & 0.76 & 0.56 \\
\hline 10 & 0.31 & 0.77 & 0.28 \\
\hline 15 & 0.21 & 0.77 & 0.19 \\
\hline 20 & 0.16 & 0.77 & 0.13 \\
\hline 25 & 0.13 & 0.77 & 0.11 \\
\hline
\end{tabular}

B. Effect of Portfolio Constraints on Welfare

\begin{tabular}{|c|c|c|c|c|c|c|}
\hline \multirow{2}{*}{$\begin{array}{l}\text { Risk } \\
\text { Aversion, } \\
\sigma\end{array}$} & \multicolumn{2}{|c|}{ Constrained? } & \multirow{2}{*}{$\begin{array}{l}\text { Constr./ } \\
\text { Unconstr. }\end{array}$} & \multicolumn{2}{|c|}{ Constrained? } & \multirow{2}{*}{$\begin{array}{r}\text { Constr./ } \\
\text { Unconstr }\end{array}$} \\
\hline & No & Yes & & No & Yes & \\
\hline & \multicolumn{3}{|c|}{5 Years } & \multicolumn{3}{|c|}{10 Years } \\
\hline 2 & 11.09 & 8.21 & 0.74 & 25.85 & 18.88 & 0.73 \\
\hline 3 & 7.30 & 5.89 & 0.81 & 16.68 & 13.37 & 0.80 \\
\hline 4 & 5.44 & 4.39 & 0.81 & 12.31 & 9.89 & 0.80 \\
\hline 5 & 4.33 & 3.49 & 0.81 & 9.75 & 7.84 & 0.80 \\
\hline 10 & 2.14 & 1.73 & 0.81 & 4.78 & 3.86 & 0.81 \\
\hline 15 & 1.42 & 1.15 & 0.81 & 3.16 & 2.56 & 0.81 \\
\hline 20 & 1.06 & 0.86 & 0.81 & 2.37 & 1.91 & 0.81 \\
\hline \multirow[t]{2}{*}{25} & 0.85 & 0.69 & 0.81 & 1.89 & 1.53 & 0.81 \\
\hline & \multicolumn{3}{|c|}{15 Years } & \multicolumn{3}{|c|}{25 Years } \\
\hline 2 & 41.51 & 29.95 & 0.72 & 75.03 & 53.00 & 0.71 \\
\hline 3 & 26.27 & 20.95 & 0.80 & 45.82 & 36.19 & 0.79 \\
\hline 4 & 19.22 & 15.38 & 0.80 & 33.02 & 26.25 & 0.79 \\
\hline 5 & 15.15 & 12.16 & 0.80 & 25.82 & 20.60 & 0.80 \\
\hline 10 & 7.36 & 5.93 & 0.81 & 12.36 & 9.93 & 0.80 \\
\hline 15 & 4.86 & 3.92 & 0.81 & 8.12 & 6.54 & 0.81 \\
\hline 20 & 3.63 & 2.93 & 0.81 & 6.05 & 4.88 & 0.81 \\
\hline 25 & 2.90 & 2.34 & 0.81 & 4.82 & 3.89 & 0.81 \\
\hline
\end{tabular}

Note: Foreign portfolio is Far East equity portfolio. 


\section{Effects of Social Security Reform on Various Wealth Groups}

In section 10.1 above, we noted that social security represented varying fractions of financial wealth for different income classes of workers at the retirement point. Retirement wealth was mostly social security and housing for the poorest Americans, while it was a much smaller fraction for more affluent citizens.

The benefits discussed above accrued to a household moving from an initial position in which all wealth is invested in safe assets to a new position in which the individual holds an optimal retirement portfolio, abstracting from any consideration of subsistence consumption. We can use our modifications of the basic consumption-investment problem, which introduced social security benefits and subsistence consumption, to determine the implications for various wealth groups of broadening the menu of retirement assets.

Rich Retirees. There may be little benefit to rich retirees of introducing the possibility of risky investment during retirement since these retirees have substantial non-social security, nonhousing wealth. Therefore, when they are endowed with a benefit by the social security system during retirement, they will simply hold fewer riskless assets in their portfolios. In fact, they might well not exercise the new right to reallocate their social security wealth away from its existing form since they had already reallocated other parts of their portfolio.

In terms of the analysis presented above, the demand for risky assets on the part of rich retirees would be

$$
\left(x_{d}+x_{i}\right)\left[a_{t}+\sum_{j=0}^{T-R}\left(\frac{1}{1+r_{b}}\right)^{j} \underline{b}_{t+j}\right]
$$

that is, it would be proportional to financial wealth plus the present value of social security payments. Higher social security benefits would raise the demand for risky assets. The demand for riskless bonds would be a little more complicated:

$$
\left(1-x_{d}-x_{i}\right)\left[a_{t}+\sum_{j=0}^{T-R}\left(\frac{1}{1+r_{b}}\right)^{j} \underline{b}_{t+j}\right]-\sum_{j=0}^{T-R}\left(\frac{1}{1+r_{b}}\right)^{j} \underline{b}_{t+j} .
$$

This demand would be a fraction of total wealth, including financial assets and social security payments, but one would then net out the quantity of riskless assets that the social security claim implicitly represents. Higher social security payments would reduce the demands for riskless assets since the demand can be rewritten as 


$$
\left(1-x_{d}-x_{i}\right) q_{t}-\left(x_{d}+x_{i}\right)\left[\sum_{j=0}^{T-R}\left(\frac{1}{1+r_{b}}\right)^{j} \underline{b}_{t+j}\right] .
$$

Further, if the government allowed (or required) these individuals to have a risky social security claim, then they would reduce risky assets in private retirement accounts so that their net portfolio shares were $x_{d}$ and $x_{i}$.

Poor Retirees. Now consider a poor retiree whose income consists only of social security distributions and who has little or no financial wealth apart from the claim on the social security system. If this individual has a subsistence consumption level that is a large fraction of social security wealth, then he too would not reallocate much of a privatized social security account toward risky assets. That is, if this individual has a small level of our modified wealth measure,

$$
\hat{a}_{t}=\left[a_{t}+\sum_{j=0}^{T-R}\left(\frac{1}{1+r_{b}}\right)^{j}\left(\underline{b}_{t+j}-\underline{c}_{t+j}\right)\right],
$$

then he would have little demand for risky assets. Yet a poor retiree without substantial subsistence consumption requirements - one with a low level of financial wealth, for whom social security payments are the main basis for retirement consumption-would get the larger welfare gains from investing in risky assets, as discussed above.

\subsubsection{Optimal Portfolios with an Uncertain Lifetime}

We now turn to investigating a situation in which individuals have uncertain lifetimes. We assume that individuals can purchase annuities from a competitive, zero-cost insurance company. There are two effects of this modification, relative to our prior analysis of the certain-lifetime case. First, in the presence of less than certain survival, individuals effectively discount the future more heavily and wish to tilt their consumption profiles toward the present. Second, in the presence of less than certain survival, insurance companies price the longer-term components of annuities more cheaply, thus encouraging individuals to substitute toward the future. When annuities are priced in an actuarially fair manner, as we will assume, then these two substitution responses offset each other. Individuals can then simply purchase a higher level of consumption in all periods in which they are alive. The portfolio shares of risky assets - held by the insurance company in response to the preferences of households - are unaffected by uncertain lifetimes.

We assume that there are insurance companies that offer annuities with returns linked to the returns on risky assets. Suppose that a competitive, zero-cost insurance company faces a population of individuals with actuarial survival probabilities $\pi_{j}$ (i.e., $\pi_{j}$ denotes the probability that an indi- 
vidual is alive at age $j$ ). Then the insurance company could offer certain, real annuities (backed by bonds) to retirement-age individuals. In particular, the insurance company would offer annuities that took the following general form to an individual retiring at date $t$, considering the allocation of retirement wealth at $t+1$ so as to support consumption in the $T-R$ periods $t+1, t+2, \ldots, t+T-R$. The insurance company will provide the individual with a specified pattern of consumption beginning at $t+1$ (conditional on survival) and lasting for the remainder of his retirement life. In return, the individual or his estate would turn over

$$
\sum_{j=1}^{T-R} \pi_{j}\left(\frac{1}{1+r_{b}}\right)^{j-1} c_{t+j}
$$

units of bonds to the insurance company at date $t+1$. That is, the price of the annuity increases with the survival probabilities and the level of real payments but falls with the real interest rate.

The top panel of figure 10.4 shows the U.S. survival probabilities, conditional on attaining sixty-five years of age, based on the general population. The expected remaining lifetime for such an individual is about 17.5 years. We use these survival probabilities in all our computations below, although it would be interesting to explore how certain computations would
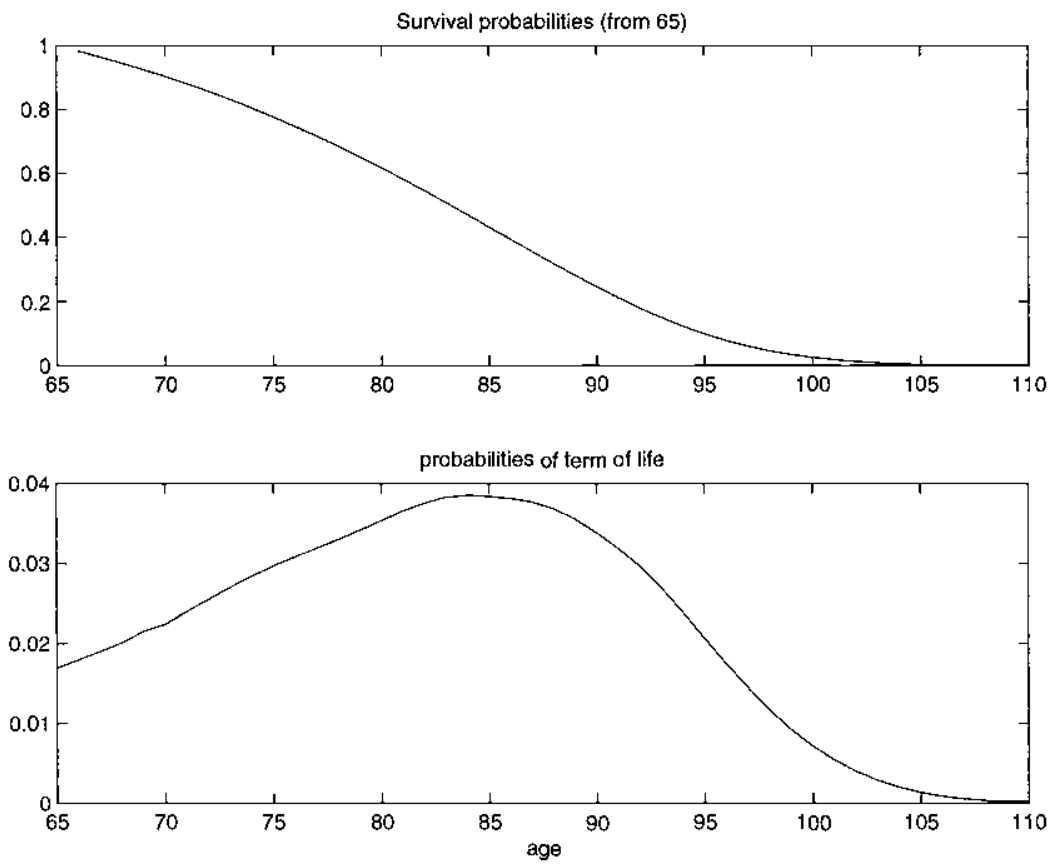

Fig. 10.4 U.S. survival probabilities 


\begin{tabular}{lccccc}
\hline & \multicolumn{5}{c}{ Real Interest Rate } \\
\cline { 2 - 6 } & .00 & .01 & .02 & .03 & .04 \\
\hline Annuity growth rate: & & & & & \\
.00 & 17.48 & 15.77 & 14.33 & 13.09 & 12.04 \\
.01 & 19.49 & 17.48 & 15.79 & 14.35 & 13.13 \\
.02 & 21.85 & 19.47 & 17.48 & 15.80 & 14.38 \\
.03 & 24.62 & 21.80 & 19.45 & 17.48 & 15.82 \\
.04 & 27.90 & 24.53 & 21.75 & 19.42 & 17.48 \\
\hline
\end{tabular}

differ for subgroups of the population that have alternative survival probabilities. Table 10.15 presents annuity factors under actuarial fair insurance and at various real interest rates. ${ }^{22}$ This table shows that a real interest rate of 2 percent and the U.S. survival probabilities imply that the price of an annuity paying a level real stream is $\$ 14.33$ per dollar of annuity payment. The table also reports prices of real annuities that grow at various rates.

To help us think about more complicated annuities that the insurance company might offer, it is useful first to think about the insurance company's balance sheet under the assumption that such riskless annuities are "backed" by insurance-company investments in the safe bond. The insurance company would begin with $b$ dollars per investor at date $t+1$, and it would pay each of the surviving investors $c$ at this date so that it would have $b_{t+2}=\left(1+r_{b}\right)\left(b_{t+1}-\pi_{1} c_{t+1}\right)$ in the next period (period $\left.t+2\right)$. In later periods, the evolution of the insurance company's bonds would satisfy $b_{t+j+1}=\left(1+r_{b}\right)\left(b_{t+j}-\pi_{j} c_{t+j}\right){ }^{23}$

More generally, such an insurance company could hold any underlying assets and make any feasible payment pattern to its group of retirees. For example, if the insurance company held a portfolio of bonds, domestic assets, and risky assets that bore random return $\tilde{r}$, then the disbursements to the annuityholders would be constrained by the sequence of wealthaccumulation constraints $a_{t+j+1}=\left(1+\tilde{r}_{t+j+1}\right)\left(a_{t+j}-\pi_{j} c_{t+j}\right)$. We can accordingly think about the optimal annuity package that our household would select given its utility function.

If we were to analyze the optimal portfolio/annuity problem for an individual with an uncertain lifetime, there would be the following generaliza-

22. The elements in this table are

$$
\sum_{j=1}^{T-R} \pi_{j}\left(\frac{1+\gamma}{1+r_{b}}\right)^{j-1}
$$

for various real growth rates and real interest rates, using the U.S. survival probabilities.

23. Imposing $c_{t+j}=\left(1+\gamma^{j-1}\right) c_{t+1}$, and solving this difference equation subject to the terminal condition $b_{T+1}=0$, leads to the present-value annuity formula reported in the text. 
tions of the standard consumption-investment portfolio problem: the marginal propensity to consume out of wealth depends on the extent of the individual's uncertainty about his or her horizon, but the portfolio shares are exactly those that are relevant in the model with a certain horizon. Further, we would find a value function that incorporates the uncertainty that individuals have about their lifetimes, which takes the general form of that in the standard problem, that is, $v(a)=(1 / 1-\sigma)[q a]^{1-\sigma}$, with the $q$ now depending on survival probabilities as well as the distribution of portfolio returns, time preference, and risk aversion. Hence, there are two general lessons that we describe in the next two subsections.

\section{The Optimal Retirement Account Is a Variable Annuity}

The optimal package of retirement benefits is a variable annuity where the return is linked to the returns on risky investments. This retirement annuity combines portfolio management with the sharing of life risks. Individuals earn higher average returns on this account, relative to the current "flat" annuity provided by social security, because the insurance company holds some risky assets in its portfolio. Yet, since the insurance company can pool the risks of uncertain lifetime for individuals, as with fixed-payment annuities, it can provide each individual with a higher level of consumption than would be the case if the individual had to hold the risky assets directly and guard against the risks of uncertain lifetime by himself.

\section{Benefits from Including Risky Assets in the Retirement Annuity}

With annuitization of retirement wealth, the effects of portfolio composition can be explored in the same manner that we used in the analysis of certain lifetimes presented above. These results are reported in table 10.16.

There are important benefits to holding a variable annuity for all but

Table 10.16 Effects of Portfolio Constraints with Uncertain Lifetime

\begin{tabular}{lrrr} 
& \multicolumn{3}{c}{ Expected Retirement $=17.5$ Years } \\
\cline { 2 - 3 } & \multicolumn{2}{c}{ Constrained? } & $\begin{array}{c}\text { Constr./ } \\
\text { Unconstr. }\end{array}$ \\
\cline { 2 - 3 } Risk Aversion, $\sigma$ & No & Yes & .72 \\
2 & 61.08 & 43.80 & .80 \\
3 & 37.94 & 30.20 & .80 \\
4 & 27.59 & 22.07 & .80 \\
5 & 21.70 & 17.41 & .81 \\
10 & 10.52 & 8.48 & .81 \\
15 & 6.95 & 5.61 & .81 \\
20 & 5.19 & 4.19 & .81 \\
25 & 4.14 & 3.34 & \\
\hline
\end{tabular}


the most risk-averse investors. There are also additional benefits to international diversification. Since the life table used in constructing figure 10.4 implies that the expected lifetime is about 17.5 years, the results in table 10.16 are intermediate to those shown in table 10.14 above for certain retirement periods of fifteen and twenty-five years.

For example, when the individual has a risk-aversion coefficient of $\sigma=$ 5 , then allowing the retirement portfolio's returns to depend on risky assets would produce a utility gain that is equivalent to an increase in wealth of 21.7 percent. Most of this gain could be achieved from investing in either domestic stocks or international stocks alone. However, moving from a portfolio of domestic stocks to a fully diversified portfolio yields an increase in the wealth equivalent from 17.4 to 21.7 percent. As before, larger gains would accrue to less risk-averse retirees and smaller ones to retirees who were more risk averse.

\subsection{Life-Cycle Portfolio Choice and Nontraded Assets}

This section sketches a life-cycle model of portfolio choice that we use to discuss the importance of international investment during the accumulation phase of a privatized social security system. There are two main lessons that we draw from the analysis. First, nontraded assets such as human capital and social security can affect the demands for traded financial assets. Second, the hedging demand for traded financial assets depends importantly on the persistence of income shocks and the degree to which these shocks are correlated with the returns on traded financial assets.

\subsubsection{A Model of Life-Cycle Saving}

An individual living in this economy is economically active from an initial working date, at which time his age is $\gamma=0$, until his death at age $\gamma=T$. A worker who is young $(\gamma=0)$ in period $t$ will maximize the expected value of discounted lifetime utility from consumption:

$$
E_{t} \sum_{\gamma=0}^{T} \beta^{\gamma} u_{\gamma}\left(c_{t+\gamma}\right) .
$$

Note that the period utility function $u_{\gamma}$ may depend on the individual's age.

Each worker has labor income received as an endowment during the working years, denoted by $y_{0, t}, y_{1, t+1}, \ldots, y_{R, t+R}$, where $R$ is the retirement date. A typical worker has a "hump-shaped" path of lifetime income, with income rising during the early working years and then declining as the worker nears retirement. While lifetime income is expected to have this profile, a typical worker faces considerable uncertainty about the exact levels of future income. 
We model the social security system as follows. There is a social security account in which an individual's contributions $z_{\gamma t}=\tau_{\gamma t} y_{\gamma t}$ accumulate according to

$$
m_{\gamma t}=\left(1+r_{t}^{w}\right) m_{\gamma-1, t-1}+z_{\gamma t},
$$

where $r_{t}^{w}$ is the (net) growth rate of the wage-indexing series used by social security to mark up individuals' past contributions. ${ }^{24}$ Benefits, denoted by $g$, are an increasing function of accumulated contributions:

$$
g\left(m_{R t}\right), \quad g^{\prime}>0 .
$$

As before, there are three marketable financial assets: a short-term real bond, a home-country equity portfolio, and a foreign (rest-of-the-world) equity portfolio, with returns $r_{b t}, r_{d t}$, and $r_{i t}$, respectively.

Individuals' decisions regarding consumption, saving, and portfolio choice will depend on their age as well their level of wealth, their history of social security contributions and expected future benefits, and the expected returns on traded financial assets. In the equations presented below, we suppress the age subscript attached to each choice variable.

Individual decisions will satisfy the following equations:

$$
\begin{gathered}
a_{t+1}=\left[x_{b t}\left(1+r_{b, t+1}\right)+x_{d t}\left(1+r_{d, t+1}\right)+x_{i t}\left(1+r_{i, t+1}\right)\right] f_{t}, \\
1=\left[x_{b t}+x_{d t}+x_{i t}\right], \\
c_{t}+f_{t}=a_{t}+y_{t}+g_{t}-z_{t} .
\end{gathered}
$$

As before, the first of these three equations describes the evolution of portfolio wealth over time, and the second equation simply states that portfolio shares in the three traded financial assets add to one. ${ }^{25}$ Equation (17) says that the individual has financial assets $a$ and income net of taxes $y+g-$ $z$, which can be allocated between the purchase of new financial assets $f$ and current consumption $c$. The individual also has a retirement account with balance $m$. Individual income and asset returns are functions of an exogenous state vector $\delta$ that evolves as a Markov process. There is nothing about the individual's decision problem that makes it depend directly on time, although it does depend on age. Thus, we may rewrite the individual's problem in dynamic programming form as follows:

24. In this section, all lowercase variables refer to variables measured in real terms, i.e., in goods units. Otherwise, the variable definitions are the same as in sec. 10.2 above.

25. Equation (17) differs from its sec. 10.4 counterpart, eq. (14), only in that labor income $y_{t}$ and social security taxes $z_{t}$ and benefits $g_{t}$ enter on the right-hand side of the last expression as additional variables that affect wealth. A typical individual either will be working and paying taxes $z_{t}$ or will be retired and receiving benefits $g_{t}$. 


$$
\begin{aligned}
v(a & +y+g-z, m, \gamma, \delta) \\
& =\max _{c, f, x_{d}, x_{i}, x_{b}}\left\{u(c, \gamma)+E\left[v\left(a^{\prime}+y^{\prime}+g^{\prime}-z^{\prime}, m^{\prime}, \gamma^{\prime}, \delta^{\prime}\right)\right] \mid \delta\right\},
\end{aligned}
$$

subject to the equality constraints given above. This expression uses the conventional dynamic programming "prime" notation to refer to next period's asset positions, incomes, returns, and states. There may also be inequality constraints, reflecting prohibitions on the short selling of assets and borrowing against future income $\left(x_{b} \geq 0, x_{i} \geq 0, x_{d} \geq 0, f \geq 0\right)$.

In general, it is difficult to solve this type of dynamic program, even numerically. First, there is a large range for accumulated assets over the life cycle: the evidence in table 10.1 above indicates that the median retiring household had retirement assets that were roughly 40 percent of lifetime income or about sixteen times average annual income, assuming a fortyyear working life. Second, there are many periods of life: for each period, the optimal choices must be calculated as well as the associated value function. Third, many variables may be important for forecasting individual income profiles. Fourth, and finally, there are several reasonable constraints that one would like to place on individuals' choices, such as shortsales constraints on assets and constraints preventing borrowing against future income. Each of these considerations substantially increases the complexity of the computational problem. ${ }^{26}$

For the purpose of the present paper, we proceed as follows. First, we review results from the prior literature that are relevant to the current problem, and then we discuss the general form of the optimal decision regarding portfolio choice when there is uncertainty regarding future labor income and asset returns. Second, we present results on optimal portfolio choice in a situation in which marketable financial assets can be used to perfectly hedge the risk associated with labor income uncertainty.

\subsubsection{Life-Cycle Portfolio Choice under Uncertainty}

Early contributions to the social security literature studied a model of life-cycle consumption and saving without uncertainty (see, e.g., Samuelson 1958). A chief finding from that literature was that social security depresses private saving by taking away income during the work years and returning it as social security benefits during the retirement period. Lifecycle models with income uncertainty will inherit this property, but they additionally focus attention on the effects of social security on portfolio allocation.

26. In applied dynamic programming terms, the economic considerations discussed in the text mean that there is a large state space over which the value function and optimal policies must be constructed that there are many periods of life over which the value function and optimal policies must be constructed, that there are a number of "exogenous state variables" relevant to the problem, and that there are corners on the decision problem. Each of these considerations increases the complexity of the numerical dynamic programming problem. 
The dynamic programming problem for an age $\gamma$ worker was given in equation (18) above. The first-order condition for efficient choice of the portfolio share invested in domestic risky assets, $x_{d}$, under the assumption that an increase in $x_{d}$ will be offset by a corresponding decrease in the share devoted to bonds, $x_{b}$, is given by the following:

$$
E\left\{D u\left(c^{\prime}\right) f\left(r_{d}^{\prime}-r_{b}^{\prime}\right)\right\}=0 .
$$

A similar expression describes optimal choice of the international risky asset:

$$
E\left\{D u\left(c^{\prime}\right) f\left(r_{i}^{\prime}-r_{b}^{\prime}\right)\right\}=0 .
$$

To highlight the economic issues that determine optimal portfolio choice, we rewrite equations (19) and (20) as follows:

$$
\begin{gathered}
f\left\{E\left[D u\left(c^{\prime}\right)\right] E\left(r_{d}^{\prime}-r_{b}^{\prime}\right)+\operatorname{cov}\left[D u\left(c^{\prime}\right),\left(r_{d}^{\prime}-r_{b}^{\prime}\right)\right]\right\}=0, \\
f\left\{E\left[D u\left(c^{\prime}\right)\right] E\left(r_{i}^{\prime}-r_{b}^{\prime}\right)+\operatorname{cov}\left[D u\left(c^{\prime}\right),\left(r_{i}^{\prime}-r_{b}^{\prime}\right)\right]\right\}=0,
\end{gathered}
$$

where future consumption is given by

$$
c^{\prime}=\left(1+\tilde{r}^{\prime}\right) f+g^{\prime}+y^{\prime}-z^{\prime}-f^{\prime} .
$$

Equations (21) and (22) highlight the two key influences on asset demand in this life-cycle setting. The first term in each equation involves the expected (excess) return on the risky assets: the higher the expected return on the asset, the more desirable it becomes as part of a portfolio. The second term in each equation involves the covariation of future consumption with the return on the particular risky asset. An asset is more desirable if it has a high return in states of nature in which the marginal utility of consumption is high. Abstracting from variations in marginal utility due to age dependence of the period utility function, this amounts to saying that an asset is valuable when high payoffs coincide with periods in which consumption would otherwise be low.

Let us consider a specific situation suggested by the empirical work of the prior section. Consider a working individual for whom the rate of growth of wages is positively correlated with current and past domestic equity returns but is uncorrelated with current and past returns on foreign assets. For this individual, the positive covariance between domestic risky assets and consumption means that domestic risky assets are less desirable than foreign risky assets yielding the same expected return. If all individuals experienced the same covariation of labor income growth with domestic and international assets, in equilibrium the expected return on domestic risky assets would have to be higher than the expected return on international assets. If individuals differ in the extent to which labor income growth is correlated with domestic assets, then our model suggests 
that individuals with a higher correlation will hold smaller shares of domestic assets in their overall portfolio of risky assets.

The presence of social security as a nontraded asset also has implications for the structure of the portfolio of marketable assets. In particular, our preceding empirical analysis suggested that the growth of the wage index - which is approximately the return on the social security accountis positively correlated with domestic assets but not particularly correlated with international assets. Accordingly, individuals would tend to substitute away from domestic risky assets and toward safe assets and international risky assets because of risky social security returns.

\subsubsection{Portfolio Choice in the Perfect Spanning Case}

The preceding section showed that there is the potential for an important hedging motive that will work to reduce holdings of domestic marketable assets if the returns on these assets are correlated with the returns on nontraded assets such as human capital or social security.

In addition to this general point, there is an important additional issue that we discuss in this section, which relates to nontraded human capital. We show that the hedging effects are most important if income is subject to permanent changes and if these permanent changes are correlated with the returns on marketable assets. In this subsection, we describe a model that is designed to highlight this distinction, studying asset accumulation and portfolio choice under the assumption that labor income is exactly related to (perfectly spanned by) the returns on traded financial assets.

\section{Transitory Income Risks}

Suppose that age $\gamma$ labor income is linearly related to the returns on traded financial assets as follows:

$$
y_{\gamma t}=\bar{y}_{\gamma}\left[l_{b \gamma}\left(1+r_{b t}\right)+l_{d \gamma}\left(1+r_{d t}\right)+l_{i \gamma}\left(1+r_{i t}\right)\right],
$$

where $\bar{y}_{\gamma}$ is a constant "benchmark" level of age $\gamma$ income, $l_{b \gamma}$ denotes the sensitivity of age $\gamma$ labor income to the return on the risk-free bond, $l_{d \gamma}$ denotes the sensitivity of labor income to the returns on domestic risky assets, and $l_{i \gamma}$ denotes the sensitivity of labor income to foreign risky assets.

So long as the returns on the three financial assets are serially independent random variables, labor income risk is transitory in equation (24). This model of transitory income risks implies a particular hedging strategy. At date $t-1$, the household can construct a perfect hedge for future labor income by selling $l_{b \gamma} \bar{y}_{\gamma}$ units of bonds, selling $l_{d \gamma} \bar{y}_{\gamma}$ units of domestic risky assets, and selling $l_{i \gamma} \bar{y}_{\gamma}$ units of international risky assets. The revenue generated by constructing the hedge is

$$
\left[l_{b \gamma}+l_{d \gamma}+l_{i \gamma}\right] \bar{y}_{\gamma},
$$


which can also be interpreted as the date $t-1$ value of $y_{\gamma t}$. By engaging in security transactions that hedge the labor income risks perfectly, the household has essentially converted its risky labor income into a certain labor income stream. Thus, it is appropriate to value human wealth using the risk-free interest rate so that an age $\gamma$ household facing a constant, risk-free interest rate $r_{b}$ would have human wealth, or human capital, equal to ${ }^{27}$

$$
h_{\gamma t}=\sum_{j=\gamma}^{R}\left(\frac{1}{1+r_{b}}\right)^{j-\gamma-1}\left(\left[l_{b j}+l_{d j}+l_{i j}\right] \bar{y}_{j}\right) .
$$

Each worker can hedge the risk of labor income fluctuations by appropriately structuring the financial asset portfolio, working one period ahead to offset the next period's income shocks. The precise details of the portfolio construction depend on the extent to which labor income looks like a bond (as reflected in a large $l_{b j}$ ), or like a domestic risky asset $\left(l_{d j}\right)$, or like an international risky asset $\left(l_{i j}\right)$.

Having hedged future labor income, the worker then chooses his optimal (age-dependent) portfolio. To simplify matters, we assume that the household's total demand for risky assets at each age is a constant fraction of the sum of its financial and human wealth (a fraction $\rho$ of total wealth). This would in fact be the optimal policy if there were constant relativerisk-aversion utility as in section 10.3 above. Then a household with financial assets $a_{\gamma t}$ and human capital $h_{\gamma t}$ will have demand for risky assets equal to $\rho\left(a_{\gamma t}+h_{\gamma t}\right)$ and demand for riskless assets equal to $(1-\rho)\left(a_{\gamma t}+\right.$ $\left.h_{\gamma t}\right)$. Suppose further that the demand for risky assets is split between domestic assets and foreign assets, with shares $\varphi$ and $(1-\varphi)$, respectively. Then, combining the hedging and diversification motives, the net demand for domestic assets is

$$
\varphi \rho\left(a_{\gamma t}+h_{\gamma t}\right)-l_{d \gamma} \bar{y}_{\gamma}
$$

and the net demand for international assets is

$$
(1-\varphi) \rho\left(a_{\gamma t}+h_{\gamma t}\right)-l_{i \gamma} \bar{y}_{\gamma} .
$$

These expressions illustrate several aspects of the demand for assets in the presence of nontraded labor income when there is complete spanning. First, the net demands for domestic and international risky assets are simply the direct demand for risky assets (terms such as $\varphi \rho\left[a_{\gamma t}+h_{\gamma t}\right]$ ) less

27. This calculation assumes that the household first hedges its labor income during the period prior to its entry into the workforce (which would be $\gamma=-1$ in our notation) and in all subsequent periods. The discount factor applied to future age $j$ labor income is $\left(1 / 1+r_{b}\right)^{i-\gamma-1}$ because we are taking present values of the hedged cash flows, which arise at age $j-\gamma-1$. 
the hedging demand (terms such as $l_{d \gamma} \bar{y}_{\gamma}$ ). Second, when income disturbances are temporary, it is likely that the direct demand for risky assets will dominate the hedging demand since human capital is much larger than current income for most ages, as shown in table 10.7 above. That is, $h_{\gamma t}>y_{\gamma t}$. Third, the "loadings" $l_{d \gamma}$ and $l_{i \gamma}$ determine the sign of the hedging demand. If domestic labor income moved one for one with domestic security returns, then $l_{d \gamma}=1$, with $l_{i \gamma}=l_{d \gamma}=0$. In this case, explored previously by Baxter and Jermann (1997), there is a large reduction in the demand for domestic assets owing to hedging demand. The empirical analysis summarized in table 10.10 above showed a more modest level of $l_{d \gamma}$, although it still suggested $l_{d \gamma}>0$, and a likely level of $l_{i \gamma} \approx 0$.

\section{Permanent Income Risks}

We now turn to an alternative model of labor income dynamics in which there are permanent shocks to the level of an individual's income. Specifically, we assume that

$$
\begin{gathered}
y_{\gamma t}=\bar{y}_{\gamma t}, \\
\bar{y}_{\gamma t}=\bar{y}_{\gamma-1, t-1}\left[l_{b \gamma}\left(1+r_{b}\right)+l_{d \gamma}\left(1+r_{d t}\right)+l_{i \gamma}\left(1+r_{i t}\right)\right] .
\end{gathered}
$$

Our own empirical evidence, as shown in table 10.10, as well as evidence provided by Campbell et al. (chap. 11 in this volume), suggests that this is a better model of the linkages between security returns and income flows than the transitory-shock model of the preceding section. ${ }^{28}$ At the same time, this model is simplistic because it omits correlation between lagged security returns and current income flows, but it will serve to make our main point.

Since income at date $t$ is a linear combination of security returns, it can be completely hedged at $t-1$ : the individual needs to sell only $\bar{y}_{\gamma-1, t-1} l_{b \gamma}$ units of bonds, $\bar{y}_{\gamma-1, t-1} l_{d \gamma}$ units of domestic stocks, and $\bar{y}_{\gamma-1, t-1} l_{i \gamma}$ units of international stocks to accomplish this objective. Taken together, these transactions produce a date $t-1$ value of $y_{\gamma t}$ equal to

$$
\bar{y}_{\gamma-1, t-1}\left[l_{b \gamma}+l_{d \gamma}+l_{i \gamma}\right] \text {. }
$$

Note that this expression looks much like the previous one for the model with transitory shocks, except that $\bar{y}_{\gamma-1, t-1}$ replaces $\bar{y}_{\gamma}$ as the "base" level of income for period $t$.

But, while this transaction completely hedges date $t$ labor income, it is only a start on hedging human capital risk. That is, when there is a shock

28. Table 10.10 provides evidence in favor of this specification because domestic stock returns are significantly related to the growth rate of labor income. If the temporary-shock model of labor income growth were correct, there could be no significant relation between stock returns and income growth. 
to $\bar{y}_{t}$, there are implications for incomes that will be received at $t+1, t+$ $2, \ldots$ as well as at $t$. A dynamic hedging plan is necessary, one that takes into account these consequences for future cash flows. Typically, this plan requires a much greater volume of hedging transactions in domestic and international stocks than in the transitory-income case that we studied above.

To determine the nature of this plan, let us begin by defining human wealth for an individual at date $t$ and age $\gamma$ implicitly according to the recursive formula

$$
h_{\gamma t}=\left[y_{\gamma t}\right]+\frac{1}{1+r_{b}}\left[h_{\gamma+1, t+1}\right] .
$$

That is, the "hedged" value of human capital is equal to the hedged value of date $t$ income plus the hedged value of human capital next period. We find it convenient to denote these hedged values with a shorthand notation so that $\left[y_{\gamma t}\right]$ is read as "the market value at date $t-1$ of a portfolio of securities that exactly replicates the stochastic income stream $y_{\gamma t}$." We discount future human capital at a constant riskless rate because of the perfect spanning assumption.

To determine how the value of human capital is linked together at different dates and the hedging transactions on which it is based, think first about the retirement-age individual who just has $h_{R t}=\left[y_{R t}\right]$ and no value of his future human capital to worry about. Previously, we have determined that his income has date $t-1$ value equal to $\bar{y}_{r-1, t-1}\left(l_{b R}+l_{d R}\right.$ $\left.+l_{i R}\right)$. Thus, the date $t$ value of his human wealth is

$$
h_{R t}=\left[y_{R t}\right]=\bar{y}_{R-1, t-1}\left(l_{b R}+l_{d R}+l_{i R}\right)\left(1+r_{b}\right) .
$$

Now let us look at the human wealth of an individual who is age $R-1$ : his human wealth is the sum of the value of current income and future human wealth:

$$
\begin{aligned}
h_{R-1, t} & =\left[y_{R-1, t}\right]+\frac{1}{1+r_{b}}\left[h_{R, t+1}\right] \\
& =\left[y_{R-1, t}\right]+\frac{1}{1+r_{b}}\left[\bar{y}_{R-1, t}\left(l_{b R}+l_{d R}+l_{i R}\right)\left(1+r_{b}\right)\right] .
\end{aligned}
$$

The second line of this expression indicates that future human wealth is proportional to $\bar{y}_{R-1, t}$ since this variable scales all future income flows. Further, since (28) makes current income also equal to $\bar{y}_{R-1, t,}$, we can write the value of human capital as

$$
h_{R-1, t}=\left[\bar{y}_{R-1, t}\right]\left(1+\bar{l}_{R}\right)
$$


by defining the composite parameter $\bar{l}_{R}=\left(l_{b R}+l_{d R}+l_{i R}\right)$. The key point is that the time-varying "base level" of future income flows can itself be hedged with the three financial assets: it is simply necessary to make larger rearrangements than previously in recognition of changing levels of $\bar{y}$. In particular, each unit of $\bar{y}_{R-1, t}$ has a hedged value of

$$
\left[\bar{y}_{R-1, t}\right]=\bar{y}_{R-2, t-1}\left(l_{b, R-1}+l_{d, R-1}+l_{i, R-1}\right)\left(1+r_{b}\right)=\bar{y}_{R-2, t-1} \bar{l}_{R-1} .
$$

But, since there are $\left(1+\bar{l}_{R}\right)$ of these units, the total value is

$$
\left[\bar{y}_{R-1, t}\right]=\left[\bar{y}_{R-1, t}\right]\left(1+\bar{l}_{R}\right)=\bar{y}_{R-2, t-1} \bar{l}_{R-1}\left(1+r_{b}\right)\left(1+\bar{l}_{R}\right) .
$$

Thus, the value of human capital again depends proportionately on current income, and it also depends on the sensitivity of future income flows to security returns.

Proceeding in the same way, the value of human capital at any age is given by

$$
h_{\gamma t}=\bar{y}_{\gamma-1, t-1}\left(1+r_{b}\right) L_{\gamma},
$$

with the composite expression $L_{\gamma}$ obeying the recursion $L_{\gamma}=\bar{l}_{\gamma}\left(1+L_{\gamma+1}\right)$.

Overall, with income subject to permanent fluctuations, there is now a very different scale of hedging transactions for the individual: the hedging demand is now proportional to human capital rather than proportional to current income. The demand for domestic assets contains two components as above: the investment demand, which is proportional to total wealth and can be written as $\varphi \rho\left(a_{\gamma t}+h_{\gamma t}\right)$, and the hedging demand against stochastic changes in $\bar{y}_{\gamma-1, t-1}$, which is proportional to human capital. This hedging demand takes the form $l_{d, \gamma-1} h_{\gamma t}$ since it is the sensitivity of $\bar{y}_{\gamma-1, t+1}$ to domestic returns that motivates the hedging demand: the larger is $l_{d, \gamma-1}$, the larger is the hedging demand. The overall demand for domestic assets is

$$
\varphi \rho\left(a_{\gamma t}+h_{\gamma t}\right)-l_{d, \gamma-1} h_{\gamma t} .
$$

Similarly, the overall demand for international assets is

$$
(1-\varphi) \rho\left(a_{\gamma t}+h_{\gamma t}\right)-l_{i, \gamma-1} h_{\gamma t} .
$$

When income shocks are permanent, the market demands for domestic and international risky assets involve a risk-management, or hedging, component that is proportional to human capital rather than proportional to labor income, as in the temporary case (see [26] and [27] above).

\section{Some Examples}

Table 10.17 provides some examples that highlight the importance of permanent versus temporary income shocks for individuals with varying 


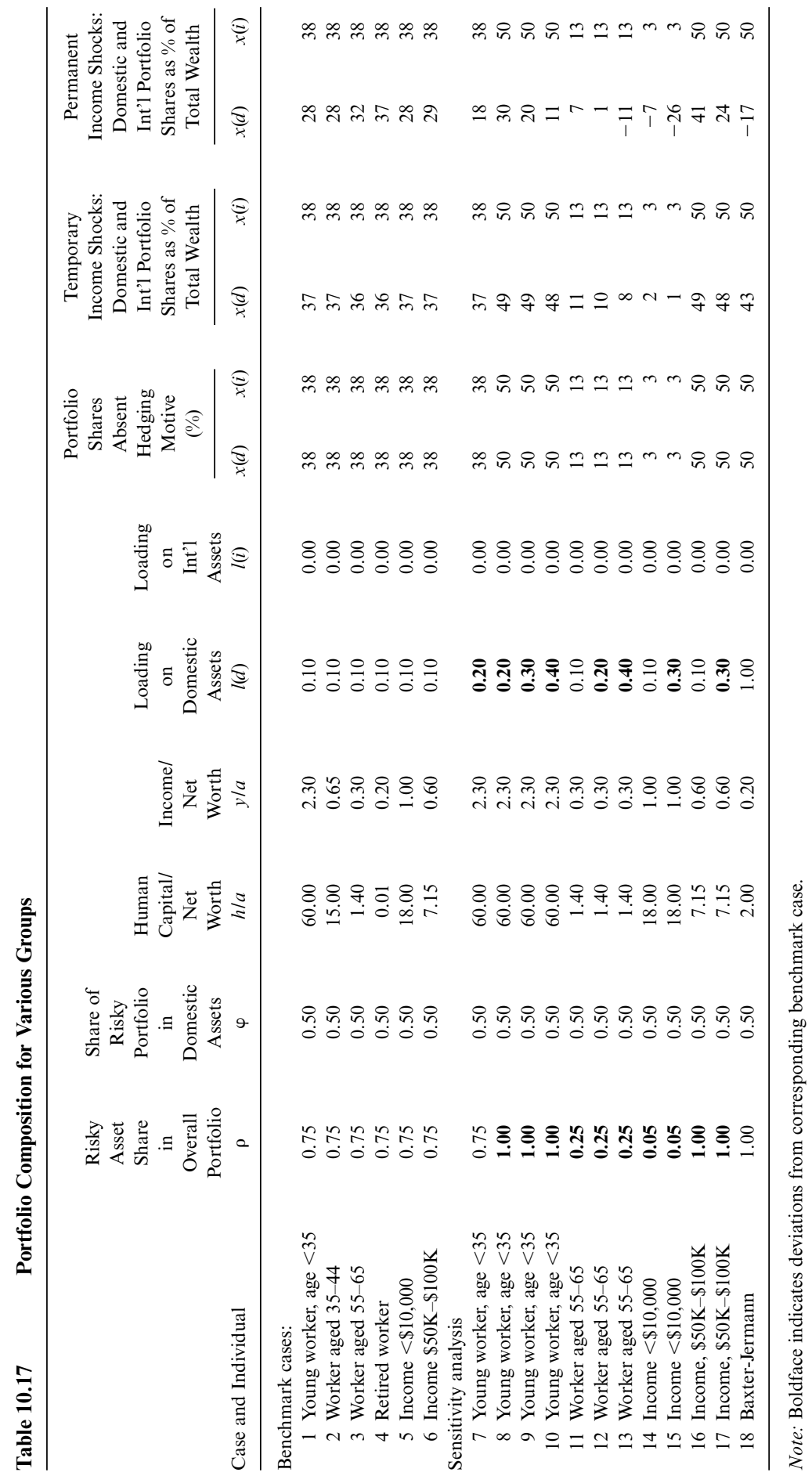


human capital-wealth ratios. The table also shows how variation in the target-portfolio shares devoted to alternative assets and variation in the asset "loadings" $l_{d, \gamma-1}$ and $l_{i, \gamma-1}$ affect overall portfolio composition:

\begin{tabular}{ccc}
\hline & Transitory Shocks & Permanent Shocks \\
\hline Domestic share & $\rho \varphi-\frac{l_{d}(y / a)}{1+(h / a)}$ & $\rho \varphi-\frac{l_{d}(h / a)}{1+(h / a)}$ \\
International share & $\rho \varphi-\frac{l_{i}(y / a)}{1+(h / a)}$ & $\rho \varphi-\frac{l_{i}(h / a)}{1+(h / a)}$ \\
\hline
\end{tabular}

To study the influence of human capital, we must specify the ratio of human capital to financial wealth, the ratio of current income to financial wealth, and the factor loadings. The first entry in table 10.17 is for a young worker under age thirty-five. From table 10.7 above, we find that a typical human capital-wealth ratio for this worker would be about 60 , while the income-wealth ratio is 2.3 . From table 10.10 above, we find that a typical loading on domestic assets might be about $l_{d, \gamma-1}=.10$, while the loading on international assets is approximately $l_{i, \gamma-1}=0$. We assume that this individual wishes to hold a share of risky assets $\rho=0.75$ and a share of international risky assets $\varphi=0.50$. Then, if there were no human capital, individuals would demand domestic and foreign risky assets in amounts each equal to $(0.75)(0.50)=0.375$, or approximately 38 percent of their wealth - this is shown in columns 9 and 10 of table 10.17 .

When we consider the hedging motive for holding risky assets, we find that there is a smaller market demand for domestic risky assets since individuals already hold a substantial amount of these through their labor income streams. When income shocks are temporary, the individual reduces his holdings of domestic assets slightly, from 38 percent of wealth to 37 percent. When income shocks are permanent, however, there is a much greater reduction in holdings of domestic assets, from 38 percent of wealth to 28 percent.

Cases 2-6 in table 10.17 present results for individuals of various ages and income levels, where the human capital/net worth and income/net worth figures are taken from table 10.7. The desired portfolio shares $\rho$ and $\varphi$ are the same as in case 1 , as are the assumed loadings $l_{d}$ and $l_{i}$. Despite the variation across these cases in the levels of human capital, income, and net worth, the overall effect on portfolios is quite similar for all workers except those near retirement. For workers close to or in retirement, the distinction between permanent and temporary shocks is of little importance.

The lower part of table 10.17 presents a sensitivity analysis, varying the desired portfolio shares and the loading on domestic assets in ways that seem empirically reasonable. These results show that the hedging effect that reduces holdings of domestic assets is most likely to lead to negative 
desired holdings of domestic assets when the desired share of risky assets in the overall portfolio, $\rho$, is low and when the loading on domestic assets, $l_{d}$, is high. In these cases, labor income is itself a risky asset that is highly correlated with domestic traded assets, so achieving a low-risk overall portfolio involves establishing a short position in traded domestic assets and using the proceeds to invest in risk-free bonds.

While the models studied in this section are very stark, they show how substantially the optimal allocation of financial wealth can differ from the actual nature of risky-asset positions when there is a very important nontraded asset. We expect that the force of hedging mechanisms would carry over into more realistic settings with constraints on the saving and investment behavior of households and additional idiosyncratic or aggregate sources of risk that would make it impossible to exactly hedge labor income with marketable financial assets.

\section{Borrowing and Short-Sales Constraints}

There are two types of constraints that are likely to be important for young workers: borrowing constraints and short-sales constraints. First, as stressed by Campbell et al. (chap. 11 in this volume), it may well be the case that young workers efficiently have very low levels of saving, possibly even negative saving, given their forecasts of future income growth. If it is impossible to borrow against future human capital, then individuals may maintain essentially zero financial assets for a dozen working years or more. A key implication for social security reform is that these individuals would benefit from having their "contributions" deferred until later in life.

Second, we have seen that households with low ratios of financial assets to human capital may wish to establish negative positions in domestic risky assets. Short-sales constraints would preclude them from holding negative quantities of domestic risky assets, and borrowing constraints would preclude them from investing more than their current financial wealth in international risky assets if their preferences would otherwise induce them to do so. As a result, if "forced saving" must take place through the social security system, then it would be beneficial to working participants to have a substantial share of its investment be in the form of international risky assets.

\subsection{Conclusion}

Plans for social security reform that incorporate public or private investment in risky assets will necessarily face the consideration of the question with which we began this chapter: Should there be investment in international risky assets?

We identified two reasons for public and private investment in international risky assets. The first is diversification benefits: by holding a portfo- 
lio that includes international risky assets, it is possible to have a less volatile portfolio return for any expected return that a public or private investor seeks to earn. The second is a risk-management benefit. If domestic labor income is more highly dependent on domestic risky-asset returns than it is on international risky-asset returns, then it is desirable for public and private investors to increase the relative importance of international investments.

We provided quantitative evidence on the potential value to risk-averse retirees of changing the certain real annuity in the social security system to an annuity whose payments would be based on international and domestic risky assets, similar to some products presently provided by the private financial system through insurance companies and purchased by sophisticated investors. These benefits depend on the extent of risk aversion, on the importance of fixed components of consumption, and on the share in retirement assets that social security payments represent. But they can be considerable, equal to a 20 percent increase in the level of retirement wealth or more, and the diversification benefit from investing in international risky assets is responsible for one-quarter of this increase.

We also showed, by example, that international risky assets could potentially play an important portfolio role during the accumulation phase of retirement saving, the prime working years. To earn high portfolio returns, it is desirable to invest in risky assets. But domestic assets have the drawback that their returns are low when labor income is low, which induces individuals to shift toward risk-free assets and international risky assets. The extent of this risk-management, or hedging, effect on portfolio composition depends on the statistical relation between human capital returns, domestic risky-asset returns, and international risky-asset returns. Our chapter accordingly provided a discussion of alternative methods of measuring human capital returns - the changes in the present value of labor incomes - and econometric evidence about the correlation between these returns and those on market financial assets. The pattern of results was consistent with there being important risk-management benefits to holding international assets since human capital returns are more highly correlated with domestic returns than with international returns.

\section{References}

Baxter, Marianne, and Urban J. Jermann. 1997. The international diversification puzzle is worse than you think. American Economic Review 87, no. 1 (March): 170-80.

Black, Fischer. 1987. Business cycles and equilibrium. New York: Basil Blackwell. 
Campbell, John Y. 1996. Understanding risk and return. Journal of Political Economy 104, no. 2 (April): 298-345.

1999. Asset prices, consumption, and the business cycle. In Handbook of Macroeconomics, ed. J. B. Taylor and M. Woodford. Amsterdam: Elsevier Science.

Davis, Steven, and Paul Willen. 1998. Using financial assets to hedge labor income risks: Estimating the benefits. University of Chicago, December. Typescript.

Fama, Eugene, and William Schwert. 1977. Human capital and capital market equilibrium. Journal of Financial Economics 4, no. 1 (January): 95-125.

Feldstein, Martin, and Andrew Samwick. 1992. Social security rules and marginal tax rates. National Tax Journal 45, no. 1 (March): 1-22.

. 1997. The economics of prefunding social security and medicare benefits. In NBER Macroeconomics Annual, ed. B. Bernanke and J. Rotemberg. Cambridge, Mass.: MIT Press.

Friedman, Benjamin, and Mark Warshawsky. 1990. The cost of annuities: Implications for saving behavior and bequests. Quarterly Journal of Economics 105, no. 1 (February): 135-54.

Friend, Irwin, and Marshall E. Blume. 1975. The demand for risky assets. American Economic Review 65, no. 5 (December): 900-922.

Gustman, Alan, Olivia Mitchell, Andrew Samwick, and Thomas Steinmeier. 1997. Pension and social security wealth in the Health and Retirement Study. NBER Working Paper no. 5912. Cambridge, Mass.: National Bureau of Economic Research, February.

Gustman, Alan, and Thomas Steinmeier. 1998. Effects of pensions on savings: Analysis with data from the Health and Retirement Study. NBER Working Paper no. 6681. Cambridge, Mass.: National Bureau of Economic Research, August.

Hakansson, Nils H. 1970. Optimal investment and consumption strategies under risk for a class of utility functions. Econometrica 38, no. 5 (September): 587-607.

Kennickell, Arthur, Martha Starr-McCluer, and Annika Sunden. 1997. Family finances in the U.S.: Recent evidence from the Survey of Consumer Finances. Federal Reserve Bulletin (January).

Kotlikoff, Laurence J., and Jeffrey Sachs. 1998. The personal security system: A framework for reforming social security. Federal Reserve Bank of St. Louis Review 80, no. 2 (March-April): 11-13.

Levhari, David, and T. N. Srinvasan. 1969. Optimal savings under uncertainty. Review of Economic Studies 36, no. 1 (April): 153-63.

Markowitz, Harry. 1959. Portfolio selection: Efficient diversification of investments. New York: Wiley.

Mitchell, Olivia, James Poterba, and Mark Warshawsky. 1997. New evidence on the money's worth of individual annuities. NBER Working Paper no. 6002. Cambridge, Mass.: National Bureau of Economic Research, April.

Samuelson, P. A. 1958. An exact consumption-loan model of interest with or without the social contrivance of money. Journal of Political Economy 66, no. 6 (December): 467-82.

. 1969. Lifetime portfolio selection by dynamic stochastic programming. Review of Economics and Statistics 51, no. 3 (August): 239-46.

Shiller, Robert J. 1993. Macro markets: Creating institutions for managing society's largest economic risks. Oxford: Clarendon.

Social Security Administration (SSA). Office of Research and Statistics. 1989. Facts and figures about social security, 1988. Washington, D.C.: U.S. Government Printing Office. 


\section{Comment David Backus}

It is a pleasure to discuss this paper, which touches on some classic issues in finance and introduces some new ones as well. I would like to discuss some of these issues on their own, then turn to specific points made in the paper.

\section{International Diversification}

Baxter and King follow a long and distinguished tradition in touting the benefits of international diversification. The theoretical argument is straightforward: adding international assets expands the investmentopportunity set, which cannot hurt. The question in practice is how large the benefits are. Since Zvi Bodie is a founding member of this group, let me quote Bodie, Kane, and Marcus (1996, 833-34) on the subject: "There is a marked reduction in risk for a portfolio that includes foreign as well as US stocks, so rational investors should invest across borders. Adding international to national investments enhances the power of portfolio diversification. Indeed, the figure indicates that the risk of an internationally diversified portfolio can be reduced to less than one half the level of a diversified US portfolio." With this kind of background, I cannot resist the temptation to argue the opposite.

Let me offer three contrarian counterarguments against the tide of sentiment in favor of international diversification, some of which are mentioned in the Bodie, Kane, and Marcus book.

Counterargument 1: The Gains Are Small. Especially for investments in the developed world (most of the available supply of marketable assets), the returns are so closely related to those in the United States that the gains from diversification are small. Consider this table adapted from Vanguard's web site:

\begin{tabular}{lcc}
\hline Portfolio & Mean Return (\%) & S.D. of Return (\%) \\
\hline 100\% domestic & 16.6 & 14.2 \\
$80 \%$ domestic, 20\% foreign & 16.4 & 13.8 \\
$50 \%$ domestic, 50\% foreign & 16.1 & 14.3 \\
\hline
\end{tabular}

(These numbers are based on annual returns between 1977 and 1997 for broad-based indexes for the United States and the developed world.) I interpret the last column as saying that the gains are small. Baxter and King's figure 10.2 is similar, in my view, in suggesting that the gains are

David Backus is professor of economics and international business at the Stern School of Business, New York University, and a research associate of the National Bureau of Economic Research. 
relatively modest. (The substantially larger gains cited by Bodie, Kane, and Marcus are based on portfolios of individual stocks, for which there is some question - for me, anyway - about the precision of the estimated correlations and the structure of the portfolios.)

Counterargument 2: Returns on Foreign Assets Are Erratic. We all know that disasters happen, and they seem to happen more often in other countries. This is especially true for emerging markets, where the correlations are small (hence a greater possibility of diversification) but the likelihood of disaster is large. I think of this as reflected in higher moments of asset returns (skewness and kurtosis, say) or possibly in return distributions in which such moments do not exist (the $\alpha$-stable class, e.g.). Either way, it is easy to imagine that disasters might reduce one's appetite for foreign investment. The key issue here is how extreme outcomes for returns on individual assets affect the distribution of returns on portfolios. Research on the subject is limited, but Longin and Solnik (1998) argue persuasively that international equity returns are more highly correlated in crashes than in general, suggesting that international diversification provides limited protection against them.

Counterargument 3: Institutional Frictions Are Greater Abroad. My colleague Ingo Walter told me a story some years ago that has stuck with me. Ingo is a pretty sophisticated investor, and he wanted to buy some Deutsche Bank stock. Deutsche Bank is hardly an obscure stock, but he estimates that the transaction costs totaled about 2.5 percent, an enormous amount by U.S. standards. Nor are local investors immune, either in Germany or elsewhere. In Walter (1998), he reports that average management fees in Chile's private pension system have been over 3 percent, even though most of the assets are domestic. Things may improve with time, but transaction costs are clearly higher outside the United States, even for developed countries. (Bodie, Kane, and Marcus [1996] have a nice summary of the developed world in table 26.4.)

A number of other "frictions" might be added to the list. For foreign investments, I would mention transparency, including accounting and disclosure standards (cf. Daimler's German and American financial statements); custody and ownership (custody fraud is a popular line of work in India and Russia); taxation (withholding tax on dividends paid to foreign investors in Canada and on capital gains in Malaysia); and traditional robbery of foreigners (Canada's forced purchase of PetroFina in the early 1980s). These frictions are potentially large, and the examples should make it clear that they are not limited to emerging markets.

In short, I would say that the days of complete and open global financial markets are still ahead of us. As of now, it is an open question how much 
international diversification one should recommend to a typical U.S. investor. That has not stopped me from making international investments, but it makes me hesitant to tell my parents to do the same.

\section{Social Security and Capital Markets}

Although they are not developed in the paper, there are several possible links between pension reform, including changes in social security programs, and the development of capital markets in general. These links are potentially more important, in a welfare sense, than the direct effect on the returns available to individuals on their retirement savings and, for that reason, are worth at least a quick mention.

The first link is between pensions and capital markets. Pension reform is invariably followed closely by changes in the structure of capital markets, typically with larger amounts of money available for investments in private equity. The United States is a striking example. Probably the biggest single factor affecting the growth of the U.S. mutual fund industry over the last fifty years has been ERISA, and much of this growth has come in equity funds. The gradual shift from defined-benefit to defined-contribution plans has created a source of funds for U.S. capital markets that issuers have been quick to tap. In the Netherlands and Chile, partial privatization of pensions led to rapid growth in the pool of marketable assets. Both countries experienced substantial increases in the ratio of market capitalization to GDP. We might expect similar developments in other countries as they change their social security systems in response to the fiscal problems facing them in the next century.

A second link is through saving. Chile remains something of a mystery, but it is clear that the privatization of social security was followed by a dramatic increase in the savings rate. One possibility is that greater efficiency in the financial system reduced the wedge between returns paid by borrowers and those received by investors.

A third link is political. I think that it is plausible that more widespread ownership of firms will change the political calculus, leading voters to demand rules with greater transparency and responsiveness to creditors. I still wonder how much of the U.S. financial system is dictated by efficiency and how much by the unusual preferences and traditions of Americans, but it is tempting to speculate that world markets will look more like those of the United States in a decade.

I think that all this matters, primarily because of the connection between capital market development with aggregate economic performance. This view is not held by everyone, but I find the work of King and Levine (1993) and Sylla (1999) (among many others) persuasive on the subject.

\section{Baxter and King}

Baxter and King extend our understanding of pensions and international diversification in several directions. One contribution is their anal- 
ysis of returns on retirement assets. In stark contrast to what one might find on Vanguard's web site or in a finance textbook, they show that over 40 percent of a typical person's assets consist of claims on the social security system. Since the returns on these claims are correlated with those on domestic assets, the benefits of international diversification in the rest of the portfolio are correspondingly larger. Another contribution is their analysis of human capital. Here, too, they show that the presence of an additional asset has substantial quantitative implications for investments in other assets. Since returns on human capital are correlated with those on equity (both are sensitive to the business cycle), international diversification is useful in hedging them. In short, the presence of social security and human capital has a substantial effect on the optimal choice of financial investments, including investments abroad.

Personally, I think that a system in which individuals invest more of their retirement assets is probably a good thing: good for them and good for the economy as a whole. Done in moderation, international diversification doubtless is a good thing, too. This paper is an ambitious attempt to quantify both and should raise the level of discussion for years to come.

\section{References}

Bodie, Zvi, Alex Kane, and Alan Marcus. 1996. Investments. 3d ed. Chicago: Irwin.

King, Robert, and Ross Levine. 1993. Finance, entrepreneurship, and growth: Theory and evidence. Journal of Monetary Economics 32:513-42.

Longin, Francois, and Bruno Solnik. 1998. Correlation structure of international equity markets during extremely volatile periods. ESSEC and HEC. Typescript.

Sylla, Richard. 1999. Emerging markets in history: The United States, Japan, and Argentina. In Global competition and integration, ed. R. Sato, R. Ramachandran, and K. Mino. Boston: Kluwer.

Walter, Ingo. 1998. The global asset management industry: Competitive structure and performance. Stern School of Business, New York University. Typescript.

\section{Discussion Summary}

James Poterba followed up on a remark by the discussant, David Backus, about the importance of transaction costs. He suggested implementing this empirically by looking, for instance, at the transaction costs charged by Vanguard for their international equity index fund and incorporating these into the construction of the mean-variance frontier. He also commented on the interplay between issues studied in the paper and annuitization. He referred to his work with Jeffrey Brown and Olivia Mitchell (chap. 9 in this volume), which finds that variable or equity-linked annuities are very attractive given the historical equity premium. Of course, one might 
question how relevant the (very generous) historical equity premium is for studying possible strategies to modify social security in the future.

Zvi Bodie noted that the NBER held its first conference on the financial aspects of the U.S. pension system in 1981. He urged everyone to read a paper presented at that occasion by Robert Merton (see Merton 1985) as it provides insights into some fundamental issues that are particularly relevant for this paper. In particular, Merton shows how social security allows agents to transfer human capital from the beginning of life to later on, when agents have insufficient human capital. Social security can thus be viewed as a way of completing markets, given that human capital is a nontradable asset. Related to this, Bodie remarked that the paper by Baxter and King identifies risk with the standard deviation of the dollar return. He argued that this technical definition has no normative content. What economists would prefer as a numeraire for measuring risk is the variability of lifetime consumption. In terms of this more appropriate definition of risk, social security may very well be a powerful way of reducing risk.

John Shoven commented on the stylized introduction to social security in the paper. The authors mention a 15.3 percent tax for social security, not noticing, however, that Medicare, disability, and other programs receive a substantial fraction out of this. Correcting for this, the tax rate for social security itself is in the neighborhood of 10 percent. Furthermore, he commented on table 10.5 , which reports a 2.4 percent mean return on social security and a 2.16 percent standard deviation. He noted that these numbers are based entirely on mean real wage growth and as such do not recognize that benefits are paid out as annuities. This ignores any effects on both the mean and the standard deviation of possible longevity improvements of changes in the retirement age or in the taxation of benefits.

Henning Bohn made two comments. First, he too criticized the computation of the return on social security. He argued that the current system clearly includes a tax on past liabilities. A measure of the return on social security therefore must consider what people get from a lifetime perspective. Moreover, the authors should distinguish between the marginal and the average return, as these would not be expected to coincide. The reason is that the current social security tax can be thought of as being partly a tax and partly forced savings. Therefore, if one considers changing marginally our investment in it, then presumably the tax is given or sunk, while on the margin one would obtain a return that may be quite different from the average return.

Second, Bohn wondered why Baxter and King focus on annual data and classify long-term government bonds as risky securities. For someone interested in achieving a constant consumption stream, a thirty-year indexed bond is probably a very safe asset. Similarly, most of the volatility in human capital is due to variations in the rate of return at which the 
income stream from wages is being discounted. This might be misleading from the perspective of someone seeking to obtain a constant consumption stream: both the present value of financing a given consumption stream and the price of a long-term bond (or the value of human capital) will change in response to fluctuations in the real interest rate. This individual is therefore not affected by interest-rate risk as the effects simply cancel out.

Stephen Zeldes remarked that figure 10.3 mixes two effects: the gain from international diversification and another gain that really derives from ignoring the unfunded liability inherent in the current social security system. The latter should not be included.

Antonio Rangel concurred and added that the policy experiment takes a dollar from the social security contributions and invests it. But, when doing so, one should acknowledge the tax increase necessary for the unfunded liabilities.

Stephen Ross noted that the moments of the returns on international investments are measured very imprecisely. Estimation risk should therefore be acknowledged in this context. Second, he remarked that the presentation of the theory of diversification could be misleading. An investor does not stand to gain when his investment-opportunity set is expanded by adding an asset with a zero alpha and an orthogonal error term with respect to the other assets. Ross argued that foreign assets are likely to satisfy these conditions. Therefore, international diversification is attractive only to the extent that it yields hedging benefits. Finally, he noted that, to put everything in the right perspective, one should realize that the market capitalization of General Electric is larger than the market capitalization of all emerging markets. Emerging markets are therefore negligible in size.

Martin Feldstein asked the authors to clarify the source of what the paper presents as the riskiness of social security. He also raised the point that the paper studies the gains of international diversification in the context of a fully developed social security system and suggested examining the potential gains during the accumulation phase as well. Finally, with respect to Poterba's remark about transaction costs, Feldstein referred to an interesting paper by Geert Bekaert and Michael Urias (1996) studying emerging markets that indicates that the efficiency gain of investing in such stocks is outweighed if the investment must be done through a country closed-end fund.

Richard Zeckhauser argued that, while emerging markets are likely to be of little importance for the American population, the reverse is definitely not true. Many emerging markets are subject to severe restrictions and regulations. Allowing investors in these countries to invest abroad, and especially in well-developed capital markets, would lead to substantial welfare gains. Second, he noted that Medicare is an important part of 
transfers to the elderly. To the extent that the elderly face risks associated with increases in the cost of medical services, one might want to consider investing in pharmaceutical companies in an effort to hedge these risks.

David Wilcox remarked that the interpretation of the equity-premium puzzle and the plausibility of the assumed degree of risk aversion $(\sigma)$ are crucial for the paper. In order to generate the portfolio behavior observed in the data (e.g., the Survey of Consumer Finances), one must assume absurd values for the coefficient of risk aversion. If Baxter and King were to use such parameter values in their analysis, the gains from diversification would likely be significantly smaller. Wilcox also pointed out that aggregate wage indexation is useful as a mechanism to make the elderly share in aggregate productivity risk and thereby reduces the risk-sharing burden on the rest of society.

In response to these comments, Robert King first clarified the methodology used to obtain the rate of return on social security. He explained how social security can be viewed in a simplified way as a wage-indexed variable annuity. King acknowledged that this simplification misses some subtleties (e.g., concerning the benefit function) but did not expect these significantly to affect the results in terms of the variability of the return as the implicit holding-period return on AIME (average indexed monthly earnings) was being calculated correctly. He added that the final version of the paper would include a section refining this measure of the risk and return on social security and discussing some of the subtleties involved.

King further stated that he agreed with Bodie's comment on the importance of risky human capital. He noted in addition that the paper uses the concept of risk in a number of different ways. The final section of the paper conducts the welfare analysis along the lines suggested by Bodie, that is, using the "normative" measure of risk.

Finally, he expressed the opinion that Ross raised an intriguing point about the uncertainty in mean returns on domestic and especially international portfolios. King proposed putting confidence intervals around the results obtained in the welfare analysis in order to take this into account.

Marianne Baxter responded to the comments of Zeldes and Rangel by noting that the analysis implicitly assumes the existence of a lump-sum tax in order to bear the unfunded liability. With respect to Wilcox's concern about a realistic value for the coefficient of relative risk aversion $(\sigma)$ in the light of the equity-premium puzzle, she noted that the data of TIAA-CREF can be rationalized using moderate parameter values, that is, $\sigma$ smaller than 20. Wilcox responded that many people consider 2 or 3 to be a reasonable value for $\sigma$. Baxter concluded that such values are virtually impossible to reconcile with the observation that half the population holds no securities at all. 


\section{References}

Bekaert, Geert, and Michael S. Urias. 1996. Diversification, integration, and emerging market closed-end funds. Journal of Finance 51 (July): 835-69.

Merton, Robert C. 1985. Insurance aspects of pensions: Comment. In Pensions, labor, and individual choice, ed. David A. Wise. Chicago: University of Chicago Press. 
